Please do not remove this page

RMIT

UNIVERSITY

\title{
A Multidimensional Dynamic Measure of Child Disadvantage: A Methodological Tool for Policymakers
}

Mishra, Ankita; Ray, Ranjan; Risse, Leonora

https://researchrepository.rmit.edu.au/esploro/outputs/9921862717201341/filesAndLinks?institution=61RMIT_INST\&index=null

Mishra, A., Ray, R., \& Risse, L. (2017). A Multidimensional Dynamic Measure of Child Disadvantage: A Methodological Tool for Policymakers. Social Indicators Research, 139, 1187-1218.

https://doi.org/10.1007/s11205-017-1742-x

Document Version: Accepted Manuscript

Published Version: https://doi.org/10.1007/s11205-017-1742-x

Repository homepage: https://researchrepository.rmit.edu.au

(C) 2017 Springer Science+Business Media B.V.

Downloaded On 2023/04/26 19:56:35 +1000

Please do not remove this page 
Thank you for downloading this document from the RMIT Research Repository.

The RMIT Research Repository is an open access database showcasing the research outputs of RMIT University researchers.

RMIT Research Repository: http://researchbank.rmit.edu.au/

\section{Citation:}

Mishra, A, Ray, R and Risse, L 2017, 'A Multidimensional Dynamic Measure of Child Disadvantage: A Methodological Tool for Policymakers', Social Indicators Research, vol. 139, pp. 1187-1218.

See this record in the RMIT Research Repository at:

https://researchbank.rmit.edu.au/view/rmit:49081

Version: Accepted Manuscript

\section{Copyright Statement:}

(C) 2017 Springer Science+Business Media B.V.

\section{Link to Published Version:}

https://dx.doi.org/10.1007/s11205-017-1742-x 


\title{
A Multidimensional Dynamic Measure of Child Disadvantage:
}

\section{A Methodological Tool for Policymakers}

\author{
Ankita Mishra ${ }^{a}$, Ranjan Ray ${ }^{b}$ and Leonora Risse ${ }^{a}$ \\ ${ }^{\mathrm{a}}$ RMIT University, Melbourne, Australia \\ ${ }^{\mathrm{b}}$ Monash University, Melbourne, Australia
}

\section{Authors' contact details}

Ankita Mishra (corresponding author), School of Economics, Finance and Marketing; RMIT University, 445 Swanston Street, Melbourne 3000, Victoria, Australia; ankita.mishra@rmit.edu.au

Ranjan Ray, Department of Economics; Monash University; Wellington Road, Clayton 3800, Victoria, Australia; ranjan.ray@monash.edu

Tel: +61 39902 0276; Fax: +6139905 5476

Leonora Risse, School of Economics, Finance and Marketing; RMIT University, 445 Swanston Street, Melbourne, Victoria 3000, Australia; leonora.risse@ rmit.edu.au 


\title{
A Multidimensional Dynamic Measure of Child Disadvantage: A Methodological Tool for Policymakers
}

\begin{abstract}
This paper demonstrates the applicability of an innovative approach towards examining child disadvantage, using a holistic, dynamic measure that not only accounts for multiple sources of disadvantage but also for the recurrence and persistence of disadvantage throughout a child's life. We analyse child disadvantage using two longitudinal surveys of the Australian child population, one of which is specific to Indigenous children, who experience notably higher rates of disadvantage. Among Australian children, we detect that poor body weight and bullying - representative of the broad dimensions of health and emotional wellbeing - should be of significant concern to policymakers. Among Indigenous children, housing conditions, schooling and exposure to risky behaviours stand out as areas of concern. By identifying the dimensions in which rates of child disadvantage are most severe, this methodological approach can help steer targeted policy actions.
\end{abstract}

JEL Classifications:

D63, I12, I31, I32, J15

\section{KEYWORDS}

Multidimensional deprivation, child disadvantage, persistence, longitudinal study, Indigenous children 


\section{Introduction}

The goal of improving child welfare and alleviating child impoverishment is a crucially important objective shared by all countries around the world. However, any efforts to address this objective can only be effective if the factors which contribute to child disadvantage can be clearly discerned. The fact that the wellbeing of children depends on their needs being adequately met across a multitude of dimensions - including health, safety, material provisions, educational development, emotional security and social inclusion - makes it a challenging task for policymakers to identify the areas in which children are experiencing the most severe instances of disadvantage and, hence, where to direct their policy attention. In addition to accounting for the fact that child wellbeing spans across a multitude of dimensions, policymakers also ideally need to identify the demographic groups of children that encounter relatively worse levels of disadvantage than others, so as to ensure that resources are being channelled towards those who are most vulnerable. The need for policy and welfare analyses to adopt a robust holistic approach towards measuring and comparing child disadvantage is the main motivation of this paper.

Our focus on childhood disadvantage makes a valuable contribution to efforts to tackle the broader issue of social and economic disadvantage among the total population, since impoverishment during childhood can set an individual on a downward trajectory towards poorer life outcomes in adulthood. By the same rationale, with the appropriate policy interventions, pathways out of disadvantage can begin during childhood (AIHW 2015). The issue of child disadvantage is one that affects the whole of society, as the children of today will form the social and human capital of tomorrow, determining a nation's economic growth and overall wellbeing in the future. 
One of the key contributions of our study is to demonstrate the development and application of a measure of disadvantage that is both multidimensional and specific to the child population. This focus on multidimensionality is already well established within the welfare literature, drawing its origins from Sen (1985) and prominently exemplified by the United Nations' country-level reporting of the Human Development Index (HDI). Following Alkire and Foster (2011), the HDI now extends to the Multidimensional Poverty Index (MPI), as applied in more recent UN Human Development Reports. Methodological advancements have also been made in the measurement of multidimensional disadvantage at a micro level of analysis, following Chakravarty and D'Ambrosio (2006), Jayaraj and Subramanian (2010) and Alkire and Foster (2011). Examples of applications include Bourguignon and Chakravarty (2003), Nicholas and Ray (2012) and Rogan (2016), while Alkire et al. (2015) provide a comprehensive review of the literature. Among the past studies which apply multidimensional measures of disadvantage to the Australian context, Martinez and Perales (2017) have examined multidimensional poverty in Australia; Scutella, Wilkins and Horn (2009) have used a multidimensional approach to provide evidence on poverty and social exclusion in Australia; and Scutella, Wilkins and Kostenko (2013) introduced dynamic elements into a multidimensional framework, distinguishing between the intensity of social exclusion at a point in time and its persistence over time. ${ }^{1}$

All of the above-cited studies, however, have examined wellbeing at a household level or among the adult population: none were designed to focus exclusively on the welfare of children, let alone vulnerable subgroups of children population. Indeed, although the measurement of poverty has a long history, a high-level focus on child poverty is relatively recent: it was only in 2006 that the UN General Assembly first adopted a universal definition

\footnotetext{
${ }^{1}$ See Saunders (2015) for an explanation of the 'social inclusion agenda' that formed the centrepiece of the social policy agenda of the Australian Government between 2007 and 2013.
} 
of child poverty (UNICEF 2007). Of the vast body of literature that examines the wellbeing of children in a developed country context, methodological approaches have tended to overlook the inherently multidimensional nature of disadvantage. Of those that have incorporated multidimensionality - such as Daly and Smith (2005), Sanson et al. (2005), Bradshaw, Hoelscher and Richardson (2007), Bastos and Machado (2009), and Kikkawa (2014) - very few have methodologically applied the axiomatic approach of Alkire and Foster (2011). The only exception, to our knowledge, is Minujin and Nandy (2012) whose collection of country-level case studies focused on the conceptualisation and measurement of child wellbeing and included several studies that adopted multidimensional measures. Building on these thematic and methodological foundations, our study helps to address these significant methodological and empirical deficiencies in the existing literature. Furthermore, Minujin and Nandy (2012) observed that "a common finding in all [studies] is that child poverty (with its negative impact on child well-being) is very prevalent. Not only is it widespread, in some instances it is on the increase" (p. 569). Such observations only heighten the need for researchers and policymakers to sustain our attention on this area.

The second key methodological contribution of this study is the application of the dynamic multidimensional disadvantage framework, as introduced in Nicholas and Ray (2012). While the growing availability of panel data has provided an impetus for the introduction of dynamic elements, such as the duration and persistence of disadvantage throughout an individual's life, into some past studies, these dynamic extensions have mainly been confined to the unidimensional context. ${ }^{2}$ Examples of applications of dynamic elements in the multidimensional context are limited, yet include Bossert, Ceriani, Chakravarty and D’Ambrosio (2012), Nicholas and Ray (2012), and Alkire et al. (2013), and Scutella, Wilkins

\footnotetext{
${ }^{2}$ Examples of recent contributions in the unidimensional context include Calvo and Dercon (2007), Foster (2007), Bossert, Chakravarty and d'Ambrosio (2010) and Gradin, del Rio and Canto (2012).
} 
and Kostenko (2013). ${ }^{3}$ To our knowledge, the present paper is the first empirical application of a dynamic multidimensional measure of disadvantage specifically designed for, and applied to, the child population in a developed nation. In terms of dynamic elements, our analysis draws a distinction between the 'persistence' and 'duration' of disadvantage. Persistence refers to the number of consecutive spells of disadvantage that a child experiences over a given period, while duration refers to the cumulative total of all spells of disadvantage experienced in that period which may or may not be consecutively timed. ${ }^{4}$ Identifying instances of ongoing or persistent disadvantage has become a significant concern for policymakers (McLachlan et al. 2013), heightening the relevance of this methodological tool. We demonstrate the applicability of this methodological approach using a representative sample of the Australian child population. The availability of longitudinal unit-record data for this sample of Australian children allows us to demonstrate how this measurement can account for the effects of persistent or recurring episodes of disadvantage over a child's life.

As the third key contribution of our study, the demographic breadth of our datasets and methodological properties of our measurement also allow us to apply our analysis in a comparative manner across sub-groups of children within the population. Given the high importance placed on improving the living standard of the Indigenous population in Australia, who are more likely to experience higher rates of impoverishment and disadvantage than the non-Indigenous population, we focus on examining the experiences of Indigenous children relative to the total the Australian child population. ${ }^{5}$ Despite living in a developed and affluent country, many Indigenous Australians experience levels of impoverishment that not only fall well below the living standards experienced by most Australians, but are on par with

\footnotetext{
${ }^{3}$ See, also, Alkire et al. (2015).

${ }^{4}$ See Bossert, Chakravarty and d'Ambrosio (2010) for a similar distinction in the unidimensional context.

${ }^{5}$ In Australia, the 'Indigenous' population refers to the Aboriginal and Torres Strait Islander people who are the original inhabitants of the land.
} 
the levels of impoverishment faced by some of the poorest populations in developing countries (AIHW 2015; Baxter 2013; SCRGSP 2016). Among some key statistics, Indigenous Australians experience a life expectancy that is ten years lower than that of nonIndigenous Australians, and a death rate that is 1.6 times higher (AIHW 2014). This methodological approach can aid policymakers' understanding of the dimensions of wellbeing where the gap between Indigenous children and non-Indigenous children generates the most profound impacts and, hence, aid in formulating targeted policy actions. The focus on comparing Indigenous and non-Indigenous wellbeing is particularly relevant in the context of the Australian Government's concerted efforts to 'close the gap' across a set of key statistical indicators of quality of life outcomes (Australian Government 2016). Additionally, in analysing the nature and extent of disadvantage experienced by the Indigenous child population in Australia, we demonstrate how the indicators used in our methodology can be tailored for the particular population of interest.

\section{Methodological premise for a multidimensional measure}

This analysis applies the multidimensional measures of disadvantage that is introduced and expounded upon in Nicholas and Ray (2012), which itself builds upon Foster, Greer and Thorbecke (1984), Atkinson (2003), and Alkire and Foster (2011). To outline the methodological foundations of this approach, it is assumed that we observe, for all $N$ individuals in the population of interest, $K$ different indicators of disadvantage at $T$ equallyspaced periods of time. We deem that child $i$ is disadvantaged in indicator $j$ at time $t$ if $x_{i j t}<h_{j}$, where $i \in\{1,2, \ldots, N\}, j \in\{1,2, \ldots, K\}, t \in\{1,2, \ldots, T\}, x_{i j t}$ is child $i$ 's attribute level in indicator $j$ at time $t$, and $h_{j}$ is a pre-determined threshold that determines whether or not a child is considered disadvantaged in a particular dimension. For each individual, 
dimension and time period, we can identify the depth of disadvantage that the child experiences as follows:

$$
d_{i j t}^{\gamma}=\left\{\begin{array}{c}
\left(1-\frac{x_{i j t}}{h_{j}}\right)^{\gamma} \text { if } x_{i j t}<h_{j} \\
0 \quad \text { otherwise }
\end{array}\right.
$$

The sensitivity parameter, $\gamma$, allows the weight given to an indicator to increase with the depth of disadvantage in that particular dimension. Since in practice it is often only feasible to set dichotomous thresholds to determine whether or not a child is deemed to be disadvantaged in a particular dimension nature (for example, whether the child has access to a certain good/service or not), this parameter becomes $\gamma=0$. In other words, $d_{i j t}^{0}=1$ when a child is disadvantaged in indicator $j$ at time $t$, and $d_{i j t}^{0}=0$ otherwise.

Each child $i$ has an individual disadvantage profile, which is a matrix $\boldsymbol{D}_{\boldsymbol{i}}=\left(\begin{array}{ccc}d_{\boldsymbol{i} 11}^{0} & \ldots & d_{\boldsymbol{i} 1 T}^{0} \\ d_{i K 1}^{0} & \ldots & d_{i K T}^{0}\end{array}\right)$ where $d_{i j t} \in\{0,1\} \forall j \in\{1,2, \ldots, K\}, \quad t \in\{1,2, \ldots, T\}$ and $i$ $\in\{1,2, \ldots, N\}$. The individual disadvantage score $\mu_{i}$ is a function $f: \boldsymbol{D}_{\boldsymbol{i}} \rightarrow \boldsymbol{R}$ where $\boldsymbol{R}$ is the set of real numbers. ${ }^{6}$ The population disadvantage profile is a vector $\boldsymbol{\rho}=\left(\mu_{1}, \ldots, \mu_{N}\right)$ of individual scores in non-decreasing order. Aggregating the individual disadvantage scores, the multidimensional disadvantage score $\Omega$ for the population is then a function $g: \boldsymbol{\rho} \rightarrow \boldsymbol{R}$ and can be represented, following Nicholas and Ray (2012), as:

$$
\Omega=\frac{\sum_{\mathrm{i}=1}^{\mathrm{N}} \frac{\mu_{i}}{\mu_{\max }}}{\mathrm{N}}
$$

\footnotetext{
${ }^{6}$ Given that $\mu_{i}$ takes as its input the $(T \mathrm{x} K)$ matrix $\boldsymbol{D}_{\boldsymbol{i}}$, there can in principle be a maximum of $2^{(T * K)}$ different types of child disadvantage scores, one for each possible permutation of the child disadvantage profile.
} 
Equation (2) can be interpreted as the averaged disadvantage score of the population of interest. In our results, we express these calculations as 'headcount rates'.

Using the counting approach, $\mu_{i}$ in Equation (2) can be specifically expressed in terms of child $i$ 's disadvantage profile pertaining to $K$ indicators and $T$ time periods, so that the equation becomes:

$$
\Omega_{\alpha}=\frac{\sum_{\mathrm{i}=1}^{\mathrm{N}}\left(\frac{\sum_{j}^{K} \sum_{t}^{T} d_{i j t}^{0}}{T * K}\right)^{\alpha}}{\mathrm{N}}
$$

$\Omega_{\alpha}$ is defined as multidimensional disadvantage score of the population of interest, where setting the parameter $\alpha \geq 0$ allows for this score to be sensitive to the distribution of disadvantage among children, in this case across time and indicators as applied in the unidimensional poverty context by Gradin et al. (2011). Equation (3) provides a generalisation of the approaches of both Jayaraj and Subramanian (2010) and Chakravarty and D'Ambrosio (2006). The duration-augmented measure proposed in Equation (3) can be seen as a multidimensional analogue to Foster's (2007) "duration-adjusted $P_{\alpha}$ measure" in the unidimensional context, which adjusts the standard headcount measure of disadvantage (or poverty) by the average number of periods of disadvantage (or poverty) experienced by the individual.

While Equation (3) incorporates the duration of disadvantage (a count of the number of time periods throughout a child's lifetime in which they are disadvantaged in a particular indicator), it does not explicitly consider persistence (a child's experience of disadvantage over consecutive time periods). Given our interest in incorporating the dynamic elements into our measure, we adopt the measure proposed by Nicholas and Ray (2012) which generalises Equation (3) to incorporate the effect of persistence. Each observation of $d_{i j t}^{0}$ is said to 
belong to a disadvantage spell, which is a sequence of uninterrupted disadvantage periods in a particular indicator. We use $c_{i j t}$ to denote the length of the disadvantage spell associated with a particular $d_{i j t}^{0}$. The generalised equation can therefore be expressed as:

$$
\mathrm{P} \Omega_{\alpha}=\frac{\sum_{\mathrm{i}=1}^{\mathrm{N}}\left(\frac{\sum_{j}^{K}\left(\sum_{t}^{T}\left[d_{i j t}^{0} * s\right]\right)}{T * K}\right)^{\alpha}}{\mathrm{N}}
$$

where $s \in[0,1]$ is a non-negative increasing function of $c_{i j t}$ that takes on the maximum value of 1 when the disadvantage in question $\left(d_{i j t}^{0}=1\right)$ is part of a $c=T$ period spell. ${ }^{7}$ Equation (4) incorporates unidimensional generalisation of persistence weights proposed by Gradin et al. (2012) into a multidimensional framework. Choosing a functional form for $s$ means explicitly defining an aggregate trade-off between one additional indicator of disadvantage or being disadvantaged for an additional consecutive period. Extending of the approach of Gradin et al. (2012) to the multidimensional context, we specify $s=\left(c_{i j t} / T\right)^{\beta}$ where $\beta \geq 0$ is a parameter that determines the sensitivity of the index to the length of disadvantage spells. ${ }^{8}$ For example, when $\beta$ is set to 1 , every additional period of disadvantage in a particular indicator increases the measure of disadvantage by the equivalent of $1 / T$ additional indicators. ${ }^{9}$ For robustness, we also consider results from $\beta=3$ and $\beta=5$ in the empirical application.

\footnotetext{
${ }^{7}$ Equation (4) moves beyond a simple counting approach since it uses information on permutations of disadvantage across the time dimension, and not simply combinations.

${ }^{8}$ The three parameters used in this study, $\alpha, \beta$, and $\gamma$, correspond to the same parameters in Gradin et al.'s (2012) unidimensional model, except that $\alpha$ only applies to disadvantage across time in their specification, whereas $\alpha$ applies to both time and indicators here.

${ }^{9}$ As a numerical example, consider a child's disadvantage profile for one indicator $(K=1)$ over four time periods $(T=4)$ : let us suppose this child's profile is denoted as $\boldsymbol{D}_{\boldsymbol{i}}=(1,1,0,0)$ indicating that they are disadvantaged for the first 2 of the 4 possible time periods. Using Equation (4) and $s=\left(c_{i j t} / T\right)$, we compute the child's individual disadvantage score as $\mu_{i}=\left(\frac{1 * 2 / 4+1 * 2 / 4+0 * 2 / 4+0 * 2 / 4}{4}\right)^{\alpha}$, where each
} 
The disadvantage measure computed by $\mathrm{P} \Omega_{\propto}$ in Equation (4) is therefore defined as persistence-augmented disadvantage score. For a single indicator (that is, $K=1$ ), the dynamic unidimensional disadvantage measure becomes:

$$
\left.\mathrm{P} \Omega_{\alpha}\right|_{1}=\frac{\sum_{\mathrm{i}=1}^{\mathrm{N}}\left(\frac{\sum_{t}^{T}\left[d_{i 1 t}^{0} *\left(\frac{c_{i 1 t}}{T}\right)^{\beta}\right]}{T}\right)^{\alpha}}{\mathrm{N}}
$$

The dynamic multidimensional disadvantage measure used here satisfies the properties of: subgroup decomposability, normalisation, dimensional monotonicity; durational monotonicity; dimensional transfer principle; and durational transfer principle ${ }^{10}$. The property of subgroup decomposability is particularly useful in providing a framework for comparing Indigenous and non-Indigenous children. The construction of the disadvantage measurement is such that a higher value of the disadvantage score is commensurate with a more impoverished level of wellbeing.

\section{Empirical application to the Australian child population}

\section{Dimensions of disadvantage}

The guiding principle for our choice of disadvantage dimensions is to extend the focus from solely pecuniary-based dimensions to also encompass non-monetary aspects of wellbeing. This aligns with the UN Convention on the Rights of the Child (CRC) which offers a normative framework for the understanding of children's wellbeing. CRC promotes a holistic

of the two periods of disadvantage $(t=1,2)$ is multiplied by $(2 / 4)$, giving weight to the fact that they belong to a spell of 2 out of a possible of 4 periods.

${ }^{10}$ For more details on the properties of these disadvantage measures, refer to Nicholas and Ray (2012). 
view of the child, giving equal weight to children's civic, political, social, economic and cultural rights, highlighting that such rights are interrelated, universal and indivisible. Although it is well recognised that child wellbeing is important in shaping an individual's education and employability in their adult years, the CRC emphasises that children's wellbeing during an individual's childhood years is an important measure to focus on in its own right (Bradshaw et al. 2007). ${ }^{11}$

A total of seven dimensions of child disadvantage are encompassed in this study: health, family relationships, community connectedness, material wellbeing, educational wellbeing, emotional wellbeing and exposure to risky behaviours. These dimensions are in line with the child wellbeing dimensions considered for economically advanced nations (Heshmati et. al 2008). For each dimension, we need to identify at least one variable in the data which could adequately represent the dimension. Our choice of variables for these indicators was chiefly guided by data availability, as explained below. Following Atkinson (2003), all of the indicators are weighted equally. ${ }^{12}$

\footnotetext{
${ }^{11}$ The CRC was signed on 20 November 1989 and came into force on 2 September 1990 (Office of the High Commissioner, United Nations Human Rights (undated)). The notion of 'child poverty' did not explicitly appear in the CRC, although we note that a universally accepted definition of child poverty was not adopted within the UN until 2006.

${ }^{12}$ To test the robustness of our results to different weighting patterns, we repeat the calculations by varying the weighting schemes over the seven dimensions of child wellbeing. Results are available on request from the authors.
} 


\section{Datasets and representative indicators of disadvantage}

To quantify and analyse the wellbeing of Australian children, this study uses data available from the Longitudinal Study of Australian Children (LSAC). The LSAC is a geographically representative nation-wide survey of all Australian children which started in 2004 and is conducted every two years. Our analysis uses the 'K-cohort' of children who were born between March 1999 and February 2000. We use wave 1 through to wave 5 of the LSAC which enables us to track children from the age of 4-5 years to 12-13 years. Our analysis only includes children who were present in the all the five waves. After cleaning the data for missing observations and invalid responses, a total of 3557 children are available for each wave, comprising our balanced panel.

Given that, in Australia, there is significant concern over impoverished living standards and poorer lifetime outcomes that afflict the Indigenous population, our study demonstrates the way in which the indicators need be tailored to befit the circumstances of the population of interest. To analyse the extent and nature of disadvantage among the Australian Indigenous child population, we use data from the Longitudinal Study of Indigenous Children (LSIC). LSIC is a geographically-representative survey of Indigenous Australian children, which began in 2008 and is collected annually. We use the 'K-cohort' of children who were born between December 2003 and November 2004. Our study uses waves 1 to 6 of the data, which follow children from $3 \frac{1}{2}-5$ years of age up to age $81 / 2-10$ years. After we construct a balanced panel comprised only of children who participated in all six waves of LSIC, and account for missing or invalid observations, there remains a total of 321 Indigenous children

The surveys share a common objective which, generally expressed, is to identify ways to improve the wellbeing of Australian children. More specifically, LSAC, which is a 
geographically representative sample of the total Australian child population, aims to “identify policy opportunities for improving support for children and their families and for early intervention and prevention strategies". ${ }^{13}$ LSIC acknowledges the particular circumstances facing Indigenous children, specifically articulating its objective to "improve understanding of issues faced by Aboriginal and Torres Strait Islander children, their families and communities [and] improve the policy response to these issues". ${ }^{14}$ As such, LSIC has formulated survey questions that are specifically designed to inform policies aiming to improve the wellbeing of Indigenous children. While the majority of the survey items used in this analysis are common to both the LSIC and LSAC datasets, there are some differences that reflect LSIC's cultural specificity and the more difficult circumstances that Indigenous children are more likely to experience compared to non-Indigenous children. These points of difference between some of the indicators enable us to develop culturally-sensitive measurements. An additional point of difference between the two datasets is that there are some marginal differences in the way that the children's age groups are categorised, which we acknowledge in the presentation of the results.

A description of the indicators used for each dimension for the LSAC and LSIC datasets are presented in Tables 1 and 2 respectively. The variables have been designed so that the individual's state of disadvantage takes a value of $d=1$ (instead of $d=0$ ) if they satisfy the criteria for disadvantage. In some circumstances, it is the absence of a factor which enhances wellbeing that generates the state of disadvantage. In other circumstances, it is the presence of a factor which diminishes well-being that generates the state of disadvantage. Whether the

\footnotetext{
${ }^{13}$ As stated on the LSAC website www.growingupinaustralia.gov.au

${ }^{14}$ As stated on the LSIC website www.dss.gov.au/about-the-department/national-centre-forlongitudinal-studies/overview-of-footprints-in-time-the-longitudinal-study-of-indigenous-children-lsic
} 
state of disadvantage is defined positively (by virtue of the having of a factor) or negatively (by virtue of not having a factor) does not matter for the purposes of our calculations.

For both the datasets, the child is the sampling unit and responses are collected from the questionnaires completed by the main caregiver (who is usually a parent) and the child's teacher. ${ }^{15}$ The survey questions from the questionnaires, and the parameters as used to categorise a child as disadvantaged, are provided in detail in Appendix tables A1 for LSAC and A2 for LSIC.

\section{Place Table 1 here}

\section{Place Table 2 here}

The main differences in the indicators used for the total sample of Australian children in LSAC and for the Indigenous children sample in LSIC relate to material wellbeing, educational wellbeing and community connectedness. These differences are sensitive to some of the most notable disparities in quality of life that are observed between these two demographic groups, including the fact that Indigenous population have statistically much lower rates of school attendance, higher rates of housing overcrowding and more excessive alcohol consumption in the community (SCRGSP 2016). This means that, when specifically examining some dimensions of Indigenous child wellbeing, it is relatively more informative to focus on the fulfilment of children's fundamental needs, such as their right to attend school and to live in safe and suitable housing. To determine the material wellbeing of Indigenous children, we focus on the adequacy of housing conditions, while for total sample of Australian children, the threshold for material wellbeing is represented by the availability of

\footnotetext{
${ }^{15}$ For more information on survey design and sampling methodologies, refer to the LSAC Data User Guide (available through the 'Growing Up in Australia' website www.growingupinaustralia.gov.au/data/docs/userguide.pdf) and the LSIC User Guide (available through the Australian Department of Social Services website www.dss.gov.au/sites/default/files/documents/04_2015/data_user_guide_-_release_6.0.pdf).
} 
additional opportunities for development. To represent the educational wellbeing of Indigenous children, we use school attendance rates and the degree to which educational resources are available to facilitate the parental involvement, while the educational wellbeing of Australian children is represented by the child's educational performance and the degree of parental involvement. Community connectedness for Indigenous children is assessed in terms of the safety and suitability of the community, while for Australian children more generally we use their rates of participation of children in community activities.

\section{Subgroup decompositions}

As a further method for comparison, our analysis makes use of the fact that our total balanced panel of Australian children in LSAC (comprised of 3,557 children) contains 89 Indigenous children (equivalent to around $2.5 \%$ which is close to the proportion of Indigenous people in the total Australian population). For comparative purposes, we constructed subgroups within the LSAC sample to differentiate between Indigenous and non-Indigenous children. Although we acknowledge that the LSAC sample is not geographically representative of the Indigenous population, this within-LSAC comparative exercise allows us to directly compare the disadvantage rates of Indigenous children to non-Indigenous using exactly the same indicators.

Given the impoverishment already faced by the Indigenous population, and the fact that geographic isolation can tend to exacerbate levels of disadvantage by limiting access to infrastructure and resources, we also use the subgroup decomposability property of our measure to examine differences within between Indigenous children who live in urban areas 
and those who live in remote areas. This element of distinction within the analysis can aid in designing targeted policy interventions. ${ }^{16}$

Before proceeding to the empirical results, we acknowledge that, despite the two surveys having been systematically designed to represent their populations as reliably as possible in terms of both sampling methodologies and questionnaire design, making comparisons between two different population groups by using two different surveys warrants caution. In particular, we acknowledge the points of difference that we cannot control - such as differences in age category classifications and the timing of the surveys, and potential cultural differences in respondent participation and attrition rates - which place limitations on the direct comparability of the survey items. Working within these limitations, wherever possible we have used indicator variables that are comparable across the two populations and thereby lead to meaningful comparisons. More generally, however, we acknowledge that meaningfully interpreting these findings also requires a wider appreciation of the broader cultural, environmental and societal differences that set the contexts for these children's life experiences.

\section{Empirical results}

\section{Measurement of indicator-specific disadvantage}

We begin by measuring the proportion of children who experience disadvantage defined by our indicator variables, computed for each age of the child's life. Presented in Table 3, the

\footnotetext{
${ }^{16}$ To identify the level of geographic remoteness of the area in which a child is living, we use a variable contained in the LSIC dataset capturing the 'level of relative isolation categorised as none, low, moderate or high/extreme. We convert into binary subgroups: 'low' (none and low categories) and 'high' (moderate and high/extreme categories). Since a small number of children changes location over time, we base these categorisation on the location in which the child spent the majority of their years. In each age group of the balanced LSIC panel, we have a sample of 276 Indigenous children in the 'low' isolated areas and 45 Indigenous children in the 'high' isolated areas.
} 
indicators in which Australian children experience the highest rates of disadvantage, expressed as headcount rates, are body weight, family outdoor activities, extra cost activities, and bullying. These results imply that Australian children's experiences of disadvantage most commonly relate to the dimensions of health, family relationships, material wellbeing and emotional wellbeing. For several indicators, rates of disadvantage tend to increase with age, namely, family outdoor activities and community activities (from age 4-5 years) and body weight and exposure to drug and alcohol problems (from age 6-7 years). These findings signal to policymakers that dimensions of wellbeing related to family relationships, community connectedness, health, and exposure to risky behaviours should be of increasing concern as children grow older. On the other hand, it is also possible for some disadvantage indicators to improve with age, such as the indicator that we use for material wellbeing which is accessibility to computers. ${ }^{17}$

\section{Place Table 3 here}

The headcount rates of disadvantage among all Indigenous children in our LSIC dataset, computed for each indicator at each age of a child's life, are illustrated in Table 4. The indicators which generate the highest rates of disadvantage among Indigenous children are body weight, housing size, housing quality, school attendance, learning resources, bullying, and drug and alcohol problems. These findings suggest that Indigenous children's experiences of disadvantage most commonly relate to health, material wellbeing, educational wellbeing, emotional wellbeing and exposure to risky behaviour. Of particular note is the finding that rates of disadvantage arising from poor health, housing conditions, and emotional wellbeing reach very high levels among the older age groups of the Indigenous children. In

\footnotetext{
${ }^{17}$ To assess whether these computations are affected by respondent attrition in the sample over time, the headcount rates are also calculated using the unbalanced panel, which are reported in parentheses in Table 3. The consistency of the numbers between the balanced and unbalanced panel calculations alleviates our concern about this potential attrition bias.
} 
some dimensions, especially exposure to risky behaviours, the proportion of Indigenous children identified as disadvantaged should be of critical concern to policymakers: from as young as $3 \frac{1}{2}-5$ years of age, four out of every ten Indigenous children are experiencing bullying; by the age of 81/2-10 years, one out of every four children does not regularly attend school; and, across all age groups, around two out of every ten Indigenous children live in a household where at least one household member has problems with drugs and/or alcohol. Even when using different indicators for the Indigenous child population for some dimensions, which effectively set a higher threshold of disadvantage for non-Indigenous children, our findings reiterate the fact that the extent of disadvantage that Indigenous children experience far exceeds that of non-Indigenous children.

\section{Place Table 4 here}

A comparison of Tables 3 and 4 shows that across nearly all indicators, Indigenous children experience higher rates of disadvantage than the full sample of Australian children. Although we apply different indicators for some dimensions, this differential is still clearly observed even among the common indicators. Of the most acute differences, rates of disadvantage in body weight are around twice as high among the Indigenous child population, and rates of exposure to alcohol and drug problems are around seven times higher. The only dimension in which Indigenous children experience relatively lower rates of disadvantage than the full sample of Australian children is family wellbeing, potentially signifying that Indigenous families tend to be more connected to the children by way of spending time with them.

\section{Measurement of aggregate disadvantage}

To compute the disadvantage score aggregated across indicators, specific to each age group, we use a special case of Equation (3) where $T=1$, and calculate $\Omega_{\alpha} \mid t$ for each age group. The values of $\Omega_{\alpha} \mid t$, calculated at three different values of the distribution weighting parameter $\alpha$, 
are presented in Figure 1. Under the assumption that the weighting applied to each incidence of disadvantage increases linearly with the number of incidences that the child experiences $(\alpha=1)$, we find that disadvantage scores fall between the ages of 4-5 years and 6-7 years, then stabilise for several years before increasing from the age 10-11 years onwards. As the distribution sensitivity increases (to $\alpha=2$ and $\alpha=3$ ), the age-based differentials start to flatten out yet the overall 'u-shaped' pattern is sustained. When examining the overall disadvantage scores according to an Indigenous child's age, presented in Figure 2, disadvantage scores are found to worsen from 31/2-5 years up to 61/2-8 years, before declining from age 71/2-9 years and stabilising by the time they reach $81 / 2-10$ years. This pattern is robust to variations in the distribution parameter $\alpha$.

\section{Place Figure 1 here}

\section{Place Figure 2 here}

A comparison of Figures 1 and 2 illustrates that, based on the particular indicators used for the respective samples, Indigenous children experience a more severe level of disadvantage than the total Australian child sample at every age range, with this differential widening with age. Under the baseline assumption that $\alpha=1$, the aggregated disadvantage score for children in LSIC aged 31/2-5 years is marginally higher than the score for children in LSAC aged 4-5 years. By the time we look at children in LSIC aged 71/2-9 years relative to children in LSAC aged 8-9 years, this differential more than doubles and is exacerbated by increases in the parameter $\alpha$.

\section{Disaggregation by subgroup}

Next we demonstrate the subgroup decomposability of this measurement tool, based on Equation (3). Firstly using LSAC, disadvantage scores are computed for the total sample of Australian children, then for the subgroups of Indigenous children who are present in LSAC 
in comparison to non-Indigenous children. The ratio between the comparative subgroups conveys the magnitude of the differential in disadvantage between them. As seen in Figure 3, the differential between Indigenous and non-Indigenous children widens as we assign greater weighting to children who are disadvantaged in more dimensions through the parameter $\alpha$, indicating the Indigenous children are more profoundly affected by the effect of multiple instances of disadvantage.

\section{Place Figure 3 here}

Secondly we apply the subgroup decomposability of our measure to the LSIC sample of Indigenous children, disaggregating the scores according to a child's remoteness of location. Our data affirm that Indigenous children living in highly isolated geographic regions face higher levels of disadvantage than those in relatively less isolated regions, with this ratio inflating as the sensitivity parameter $\alpha$ rises. Such findings suggest that multiple disadvantage has a relatively more severe impact on Indigenous children who live in geographically isolated areas, offering justification for geographically targeted policies.

\section{Place Figure 4 here}

\section{Comparative measurements of Indigenous children across datasets}

Differences in the survey methodologies of LSAC and LSIC are expected to generate disparities in our findings, as LSAC is less representative of the composition and overall geographic dispersion of the Indigenous population especially across remote areas, compared to LSIC. We exploit these differences to assess the ways in which the disadvantage rates for the Indigenous children in LSAC differ from those of the Indigenous children in LSIC, reported in Table 5. Due to the sampling methodology, the calculations derived from the LSAC data are more likely to reflect the experiences of Indigenous children living in metropolitan and urban areas, rather than those living in remote areas. As a result, we 
speculate that these calculations are likely to represent the lower bound of the level of disadvantage experienced by Indigenous children overall.

When comparing the experiences of Indigenous children in LSAC and LSIC, the most sizeable differences that we detect relate to a child's exposure to risky behaviour. Measurements of the indicator for this dimension - drug and alcohol problems in the household - are consistently found to be higher among the LSIC sample, a differential which swells to over four times the level when looking at the 8-9 years age group. This finding suggests that Indigenous children's exposure to drug and alcohol problems in remote communities confront should be an issue for targeted attention by policymakers. We also observe that rates of disadvantage for the body weight indicator deteriorate much more rapidly over age among the LSIC Indigenous children compared to the LSAC Indigenous children. From this, we could infer that Indigenous children in remote communities suffer more acutely with the issues associated with an unhealthy body weight as they grow older. On the other hand, Indigenous children in LSAC fare worse with respect to rates of bullying, from which it could be could be inferred that Indigenous children living in metropolitan or urban areas are more exposed to bullying than those living in the remote communities. It must be recognised, however, that the average level of disadvantage experienced across the entire Indigenous child population, according to both the LSAC and LSIC samples, is still disconcertingly high.

To allow for further comparisons using a set of common indicators and common parameters of disadvantage, we also compute the rates of disadvantage for non-Indigenous children in LSAC (also presented in Table 5). Comparisons between Indigenous and non-Indigenous children across these exactly common measures simply reaffirm the stark disparity in wellbeing that is observed between Indigenous and non-Indigenous children. 


\section{Place Table 5 here}

\section{Measurement of persistence-augmented disadvantage}

Our measurements of disadvantage up to this point have been based on the number of agebased periods in which a child experiences disadvantage throughout their life, which we have referred to as duration. We now consider the degree to which a child experiences disadvantage in consecutive periods, referred to as persistence. The incorporation of the effects of persistence into the overall measure is represented by Equation (4). A larger persistence-sensitivity parameter $(\beta)$ affords greater weight to longer spells of disadvantage. To discern the effects of persistence, we compare the scores presented in Figures 3 and 4 (which do not account for persistence) to the persistence-augmented scores presented in Figure 5 and 6 . For illustrative purposes, we hold constant the other sensitivity parameter at $\alpha=1$.

Examining the differentials between Indigenous and non-Indigenous children in LSAC, presented in Figure 5, we observe that progressively higher values of $\beta$ generate a widening differential between Indigenous and non-Indigenous children. This suggests that, under these parameters, Indigenous children in LSAC are affected more profoundly by the impact of persistence than non-Indigenous children. Our dynamic framework therefore shows that not only are levels of disadvantage already higher among Indigenous children to begin with, but there are circumstances in which the ongoing nature of their experiences of disadvantage intensifies this gap in wellbeing. The policy implications of this dynamic analysis are that efforts to improve the welfare of Indigenous children requires a strategy that aims to reduce both the number of dimensions in which disadvantage occurs and persistence of these experiences.

\section{Place Figure 5 here}


In Figure 6, we allow for the persistence of disadvantage over consecutive periods to have a bearing on the disadvantage score within our sample of Indigenous children in LSIC. In this case, when examining the differentials between the high and low isolation subgroups, we find that progressive increases in the value of $\beta$ have the effect of marginally narrowing the gap between high and low isolated communities. Yet, even with the incorporation of persistence, the geographic differential is still significant as, under all values of $\beta$, the ratio between the high and low isolation subgroups remains well above 1.

\section{Place Figure 6 here}

We expand our subgroups analysis by disaggregating the persistence-augmented disadvantage score according to each indicator under analysis, as per Equation (5). This allows us to detect, using commonly-defined data, the indicators in which Indigenous children are more severely disadvantaged than non-Indigenous children. We detect that acute differentials are evident across several dimensions, most profoundly in relation to body weight, extra cost activities, access to a computer, school performance, and exposure to drug and alcohol problems. These findings reaffirm that a comprehensive approach is needed to address multiple dimensions of a child's wellbeing - including health, material wellbeing, educational wellbeing, emotional wellbeing and risky behaviours - in efforts to close the gap between Indigenous and non-Indigenous children.

\section{Place Figure 7 here}

When examining the indicator-specific score ratios for the high/low isolation subgroups in LSIC, reported in Figure 8, we observe that the indicator in which children in highly isolated regions suffer relatively more profoundly is housing quality. These differentials clearly point towards the need for targeted intervention to address poor housing quality, and material 
wellbeing more broadly, in geographically remote areas if welfare levels are to improve among the most impoverished Indigenous children.

\section{Place Figure 8 here}

\section{Concluding discussion}

This study provides a practical illustration of the applicability of a dynamic multidimensional measure of disadvantage which can be used by policymakers to address the impoverished standards of living experienced by vulnerable children in a developed nation. Our study makes a key contribution to the existing literature through its recognition of the fact that wellbeing at the level of the individual child can be generated from various sources and be influenced by recurring or persistent episodes of disadvantage over time. As such, our focus on a broad spectrum of dimensions that contribute to overall wellbeing, proxied by quantifiable indicators, is a reminder that policies efforts to address disadvantage ideally need to take account of the holistic and time-variant nature of individual wellbeing. One of the next steps for analysts is to more closely investigate potential interconnections between these various instance of disadvantage, as this bears implications for policy design and effectiveness. As a preliminary investigation, we examined correlations in duration between different indicators (presented in Tables B1 to B4 in Appendix B). This correlation analysis further illustrates how examining the multiple dimensions of disadvantage collectively and simultaneously - rather than using separate measures in isolation - generates a more holistic and complete picture of a child's experiences.

Our empirical application of this methodology was made possible by the availability of longitudinal datasets which include a rich set of information about a child wellbeing, encompassing such factors as health, education, housing, family relationships, community involvement, and drug and alcohol consumption within the household. Across the total 
Australian child population, our study identifies that body weight, bullying and participation in family outdoor activities are the indicators in which children experience the highest rates of disadvantage. This suggests that the broad dimensions of wellbeing that should be of most concern in improving child welfare generally in Australia relate to health, emotional wellbeing and family relationships.

The availability of the Indigenous-specific dataset enabled us to demonstrate how indicators can be tailored to be sensitive to the particular circumstances confronting the Indigenous child population. Our study identifies that the specific dimensions which contribute the most towards disadvantage among Indigenous children relate to housing conditions, schooling, and exposure to risky behaviours. This implies that policy attention - if it is to target the most prevalent sources of sources of disadvantage among the Indigenous population - should be directed towards these dimensions. Our findings are consistent with other evidence that highlights the critical importance of housing conditions among Indigenous child wellbeing (for example, see Dockery et al. 2010), the need to target the educational outcomes of the Indigenous children (for example, see AIHW 2015; Bowes and Grace 2014; Holzinger and Biddle 2015; and Ockendon 2014), and the severity of alcohol and drug abuse among Indigenous communities (for example, see AHMAC 2017). The additional finding that geographical isolation intensifies the level of disadvantage that Indigenous children already encounter points towards the need for more targeted intervention in remote locations, which is also consistent with the wider literature (Osborne et al. 2013; SCRGSP 2016). Our paper's analysis helps to consolidate the messages of these various studies and validate policy efforts focused on improving children's wellbeing in these particular dimensions and locations.

Insofar as our methodology permits a comparison between Indigenous and non-Indigenous groups, our empirical analysis finds that rates of disadvantage, on nearly all accounts, are 
profoundly higher among Indigenous children. Our findings are consistent with other empirical analyses that have compared the wellbeing of children using the LSAC and LSIC samples, even with a different set of indicators that are more household- or parent-focused (for example, see Kikkawa 2014). In an additional contribution to the literature, we find that not only do Indigenous children experience a much higher rate of disadvantage over all dimensions, but they also shoulder the burden of more persistent spells of disadvantage throughout their childhood, which accentuates the gap between Indigenous and nonIndigenous populations.

The picture of disadvantage generated by this analysis implies that the gap in wellbeing between Indigenous and non-Indigenous populations observed during adulthood is already taking shape during childhood. This study - by offering a methodological tool to identify the dimensions in which vulnerable subgroups of the child population suffer most profoundly can be used by policymakers to inform decisions on the allocation of policy resources early on in children's lives, and ultimately sharpen the capacity for policy to improve the lives of the most disadvantaged children in our community. This policy capacity, however, is dependent on the fulfilment of several other critical policy factors, which we propose as key recommendations arising from this study.

Firstly, there is a need for a sustained investment in the ongoing collection of longitudinal data through comprehensive surveys as LSAC and LSIC. Our study has highlighted the need to continuously track the comparative experiences of children at a highly individualised and age-specific level of analysis, reflective of time-variant nature of disadvantage. Secondly, there is a need to prioritise the evaluation of the multitude of policies that are already in place aiming to alleviate Indigenous and overall child disadvantage. Rather than enact additional policies, it would be more informative to redirect available policy resources to the robust 
evaluation of existing policies, so that policy efforts can be steered towards the strategies which are identified to be effective and away from potentially ineffective ones. The results of our analysis point towards the areas of disadvantage that are most concerning and should therefore be prioritised in terms of gathering this evidence base. Thirdly, there is a need for the empirical indicators relied on to measure the outcomes of Indigenous and non-Indigenous children to, ideally, be more closely aligned across different surveys, so that policy analysts can more precisely compare the experiences of Indigenous and non-Indigenous children. Although the existence of some differences between the two datasets was a empirical limitation that we encountered in our analysis, it points towards scope for improvement in data collection processes. It also suggests that practical gains could be achieved by facilitating even stronger coordination between data collection processes and policy evaluation processes, when designing future waves of the LSAC and LSIC datasets.

Following through on these recommendations will help strengthen the basis for effective policy intervention aiming to not only bridge the gap between Indigenous and nonIndigenous children, but fundamentally raise the wellbeing of Australian children overall.

\section{Acknowledgements}

This paper uses unit-record data from 'Growing Up in Australia' (the Longitudinal Study of Australian Children conducted in partnership between the Department of Social Services (DSS), the Australian Institute of Family Studies (AIFS), and the Australian Bureau of Statistics (ABS)) and from 'Footprints in Time' (the Longitudinal Study of Indigenous Children which was initiated and is funded and managed by the Australian Government Department of Social Services (DSS)). The findings and views presented in this paper are those of the authors and should not be attributed to the DSS, the AIFS, the ABS, nor the Indigenous people and their communities involved in the study. Helpful comments from two anonymous referees, and from seminar participants in several presentations of earlier versions of the paper, are gratefully acknowledged. The usual disclaimer applies. 


\section{References}

AHMAC (Australian Health Ministers' Advisory Council). (2017). Aboriginal and Torres Strait Islander Health Performance Framework 2017 Report, AHMAC, Canberra.

AIHW (Australian Institute of Health and Welfare). (2014). Mortality and life expectancy of Indigenous Australians, 2008-2012, Cat No. IHW 140, Canberra, AIHW.

AIHW (Australian Institute of Health and Welfare). (2015). Australia's Welfare 2015. Australia's Welfare Series No. 12, Cat. No. AUS 189, Canberra, AIHW.

Alkire, S., \& Foster, J. (2011). Counting and multidimensional poverty measurement. Journal of Public Economics, 95, 476-487.

Alkire, S., Apablaza, M., Chakravarty, S., \& Yalonetzky, G. (2013). Measuring chronic multidimensional poverty: A counting approach. OPHI Working Paper No. 75, Oxford.

Alkire, S., Foster, J., Seth, S., Santos, M., Roche, J., \& Ballon, P. (2015). Multidimensional poverty measurement and analysis, Oxford University Press, Oxford.

Atkinson, A. (2003). Multidimensional deprivation: Contrasting social welfare and counting approaches. Journal of Economic Inequality, 1, 51-65.

Australian Government. (2016). Closing the Gap: Prime Minister's Report 2016 Report, Department of Prime Minister and Cabinet, Commonwealth of Australia, Canberra.

Bastos, A. \& Machado, C. (2009). Child poverty: A multidimensional measurement. International Journal of Social Economics, 36 (3), 237-251.

Baxter, J. (2013). The family circumstances and wellbeing of Indigenous and non-Indigenous children, LSAC Annual Statistical Report 2012, 149-171.

Bossert, W., Ceriani, L., Chakravarty, S., \& D’Ambrosio, C. (2012). Intertemporal material deprivation. University of Montreal, Working Paper No. 2012-06.

Bossert, W., Chakravarty S., \& D'Ambrosio, C. (2009). Multidimensional poverty and material deprivation. Society for the Study of Economic Inequality Working Paper No. 2009-129.

Bossert, W., Chakravarty, S., \& D'Ambrosio, C. (2010). Poverty and time. UNU-WIDER Working Paper No. 2010/74, United Nations University World Institute for Development Economics Research.

Bourguignon, F., \& Chakravarty, S. (2003). The measurement of multidimensional poverty, Journal of Economic Inequality, 1, 25-49.

Bowes, J., \& Grace, R. (2014). Review of early childhood parenting, education and health intervention programs for Indigenous children and families in Australia. Issues Paper no. 8 , Closing the Gap Clearinghouse.

Bradshaw, J., Hoelscher, P., \& Richardson, D. (2007). An index of child well-being in the European Union. Social Indicators Research, 80, 133-177. 
Calvo, C., \& Dercon, S. (2007). Chronic poverty and all that: the measurement of poverty over time. Working Paper No. 89, Chronic Poverty Research Centre, Manchester.

Chakravarty, S., \& D'Ambrosio, C. (2006). The measurement of social exclusion. Review of Income and Wealth, 52 (3), 377-398.

Daly, A., \& Smith, D. (2005). Indicators of risk in the wellbeing of Australian Indigenous children. Australian Review of Public Affairs, 6 (1), 39-57.

Dasgupta, P. (1993). An inquiry into well being and destitution. Oxford, Clarendon Press.

Dockery, A. M., Kendall, G., Li, J., Mehendran, A., Ong, R., \& Strazdins, L. (2010). Housing and children's development and wellbeing: A scoping study. AHURI Final Report No. 149, Australian Housing and Urban Research Institute, Melbourne.

Foster, J. E. (2007). A class of chronic poverty measures. Working Paper No. 07-W01, Department of Economics, Vanderbilt University, Nashville.

Foster, J. E., Greer, J., \& Thorbecke, E. (1984). A class of decomposable poverty measure. Econometrica, 52, 761-766.

Gradin, C., del Rio, C., \& Canto, O. (2012). Measuring poverty accounting for time. Review of Income and Wealth, 58, 330-354.

Heshmati, A., Tausch A., \& Bajalan, C. (2008). Measurement and analysis of child wellbeing in middle and high income countries. The European Journal of Comparative Economics, 5 (2), 227-286.

Holzinger, L. A., \& Biddle, N. (2015). The relationship between early childhood education and care (ECEC) and the outcomes of Indigenous children: evidence from the Longitudinal Study of Indigenous Children (LSIC). CAEPR Working Paper No. 103/2015, Centre for Aboriginal Economic Policy Research, ANU, Canberra.

Jayaraj, D. \& Subramanian, S. (2010). A Chakravarty-D'Ambrosio view of multidimensional deprivation: Some estimates for India. Economic and Political Weekly, XLV (6), 53-65.

Kikkawa, D. (2014). Multiple Disadvantage. Research Summary No. 1/2014, National Centre for Longitudinal Data, Australian Government Canberra.

Martinez, A., \& Perales, F. (2017). The dynamics of multidimensional poverty in contemporary Australia. Social Indicators Research. 130(2), 479-496.

McLachlan, R., Gilfillan, G., \& Gordon, J. (2013). Deep and Persistent Disadvantage in Australia. Staff Working Paper, Productivity Commission, Canberra.

Minujin, A., \& Nandy, S. (Eds.). (2012). Global child poverty and well-being: Measurement, concepts, policy and action. The Policy Press, Bristol, UK.

Mishra, A., Ray, R., \& Risse, L. (2016). The Multidimensional Disadvantage of Australian Children with a Comparison between Indigenous and Non-Indigenous Children. Discussion Paper No. 19/16, Department of Economics, Monash University, Melbourne. 
Nicholas, A., \& Ray, R. (2012). Duration and persistence in multidimensional deprivation: Methodology and Australian application. Economic Record, 88, 106-126.

Ockenden, L. (2014). Positive learning environments for Indigenous children and young people. Resource Sheet No. 33, Closing the Gap Clearinghouse, AIHW and AIFS, Australian Government.

Office of the High Commissioner, United National Human Rights (undated) Convention on the Rights of the Child. http://www.ohchr.org/EN/ProfessionalInterest/Pages/CRC.aspx (accessed 25 May 2017).

Osborne, K., Baum, F., \& Brown, L. (2013). What works? A review of actions addressing the social and economic determinants of Indigenous health Issues. Paper No. 7 Closing the Gap Clearinghouse, AIHW and AIFS, Australian Government.

Rogan, M. (2016). Gender and multidimensional poverty in South Africa: Applying the global multidimensional poverty index (MPI). Social Indicators Research, 126, 9871006.

Sanson, A., Misson, S., Wake, M., Zubrick, S. R., Silburn, S., Rothman, S., \& Dickenson. J. (2005). Summarising children's wellbeing: the LSAC Outcome Index, LSAC Technical Paper No. 2, Australian Institute of Family Studies, Canberra.

Saunders, P. (2015) Social inclusion, exclusion, and well-being in Australia: Meaning and measurement. Australian Journal of Social Issues, 50(2), 139-157.

SCRGSP (Steering Committee for the Review of Government Service Provision). (2016). Overcoming Indigenous disadvantage: Key indicators report. Australian Government, Canberra.

Scutella, R., Wilkins, R. \& Horn, M. (2009). Measuring poverty and social exclusion in Australia: A proposed multidimensional framework for identifying socio-economic disadvantage. Working Paper No. 4/09, Melbourne Institute of Applied Economic and Social Research, Melbourne

Scutella, R, Wilkins, R. \& Kostenko. W. (2013). Intensity and persistence of individuals' social exclusion in Australia. Australian Journal of Social Issues, 48 (3), 273-298.

Sen, A. K. (1985) Commodities and capabilities. Amsterdam, North-Holland.

UNICEF (United Nations International Children's Emergency Fund). (2007). UN General Assembly adopts powerful definition of child poverty. https://www.unicef.org/media/media 38003.html (Last updated 10 January 2007; accessed 26 June 2017) 


\section{Tables and figures}

Table 1 Description of indicators used for all Australian children in LSAC

\begin{tabular}{|c|c|c|}
\hline Dimension & Indicator(s) & Description of indicator \\
\hline \multirow[t]{2}{*}{ Health } & Weight & Measurement of child's Body Mass Index (BMI) \\
\hline & $\begin{array}{l}\text { Use of medical } \\
\text { care }\end{array}$ & $\begin{array}{l}\text { Whether the child needs or uses more medical care, mental } \\
\text { health or educational services than is usual for most children of } \\
\text { the same age }\end{array}$ \\
\hline \multirow[t]{2}{*}{$\begin{array}{l}\text { Family } \\
\text { relationships }\end{array}$} & $\begin{array}{l}\text { Home activities } \\
\text { with family }\end{array}$ & $\begin{array}{l}\text { Whether the parent involved the child in everyday home } \\
\text { activities (such as cooking or caring for pets) during the past } \\
\text { week }\end{array}$ \\
\hline & $\begin{array}{l}\text { Outdoor } \\
\text { activities with } \\
\text { family }\end{array}$ & $\begin{array}{l}\text { Whether the parent involved the child in outdoor activities } \\
\text { (such as playing games or sport) during the past week }\end{array}$ \\
\hline $\begin{array}{l}\text { Community } \\
\text { connectedness }\end{array}$ & $\begin{array}{l}\text { Community } \\
\text { activities }\end{array}$ & $\begin{array}{l}\text { Whether the child attended any community-related activities } \\
\text { (such as going to a playground, swimming pool, cinema, } \\
\text { sporting event, museum, concert, community/school event, } \\
\text { library, religious service) with the parent or other family } \\
\text { member, during the past month }\end{array}$ \\
\hline \multirow[t]{2}{*}{$\begin{array}{l}\text { Material } \\
\text { wellbeing }\end{array}$} & $\begin{array}{l}\text { Extra cost } \\
\text { activities }\end{array}$ & $\begin{array}{l}\text { Whether the child regularly participated in any extra-cost } \\
\text { activities (such as sports coaching, team sports, } \\
\text { music/art/drama lessons, community groups, language classes) } \\
\text { during the past 6-12 months }\end{array}$ \\
\hline & $\begin{array}{l}\text { Access to } \\
\text { computer }\end{array}$ & Whether the child has access to a computer or internet at home \\
\hline \multirow[t]{2}{*}{$\begin{array}{l}\text { Educational } \\
\text { wellbeing }\end{array}$} & $\begin{array}{l}\text { Talk about } \\
\text { school }\end{array}$ & Frequency with which the parent talks to the child about school \\
\hline & $\begin{array}{l}\text { School } \\
\text { performance }\end{array}$ & $\begin{array}{l}\text { Child's performance at school compared to other children of } \\
\text { the same age }\end{array}$ \\
\hline $\begin{array}{l}\text { Emotional } \\
\text { wellbeing }\end{array}$ & Bullied & $\begin{array}{l}\text { Whether the child has been bullied at school during the past } \\
\text { year }\end{array}$ \\
\hline $\begin{array}{l}\text { Exposure to } \\
\text { risky behaviour }\end{array}$ & $\begin{array}{l}\text { Drug and } \\
\text { alcohol } \\
\text { problems }\end{array}$ & $\begin{array}{l}\text { Whether anyone in the child's household had an alcohol or drug } \\
\text { problem during the past year }\end{array}$ \\
\hline
\end{tabular}

Note: Indicators are based on the questionnaire items used in the Longitudinal Study of Australian Children (LSAC). 
Table 2 Description of indicators used for Indigenous children in LSIC

\begin{tabular}{|c|c|c|}
\hline Dimension & Indicator(s) & Description of indicator \\
\hline Health & Body weight & Measurement of child's Body Mass Index (BMI) \\
\hline \multirow[t]{3}{*}{$\begin{array}{l}\text { Family } \\
\text { relationships }\end{array}$} & $\begin{array}{l}\text { Home activities } \\
\text { with family }\end{array}$ & $\begin{array}{l}\text { Whether the parent or another family member did any of the } \\
\text { following activities with the child in the past week: read a book, } \\
\text { tell a story, play indoors, housework/cooking, help with chores }\end{array}$ \\
\hline & $\begin{array}{l}\text { Outdoor } \\
\text { activities with } \\
\text { family }\end{array}$ & $\begin{array}{l}\text { Whether the parent or another family member did any of the } \\
\text { following activities with the child in the past week: play } \\
\text { outdoors, go to the playground; participate in organised } \\
\text { sports/dance activities }\end{array}$ \\
\hline & & $\begin{array}{l}\text { (If the above indicator is not available) Whether the parent } \\
\text { knows where your child is, when they are away from home }\end{array}$ \\
\hline \multirow[t]{2}{*}{$\begin{array}{l}\text { Community } \\
\text { connectedness }\end{array}$} & $\begin{array}{l}\text { Safety of } \\
\text { community }\end{array}$ & Parent's perception of the safety of the community \\
\hline & $\begin{array}{l}\text { Suitability of } \\
\text { community for } \\
\text { children }\end{array}$ & $\begin{array}{l}\text { Parent's perception of how suitable the community is for young } \\
\text { children }\end{array}$ \\
\hline \multirow[t]{2}{*}{$\begin{array}{l}\text { Material } \\
\text { wellbeing }\end{array}$} & $\begin{array}{l}\text { Housing size } \\
\text { per person }\end{array}$ & $\begin{array}{l}\text { Number of bedrooms in home, deflated/adjusted for number of } \\
\text { people in household }\end{array}$ \\
\hline & $\begin{array}{l}\text { Housing } \\
\text { quality }\end{array}$ & $\begin{array}{l}\text { Whether the home needs repairs or an important fixture is not } \\
\text { working }\end{array}$ \\
\hline \multirow[t]{2}{*}{$\begin{array}{l}\text { Educational } \\
\text { wellbeing }\end{array}$} & $\begin{array}{l}\text { School } \\
\text { attendance }\end{array}$ & $\begin{array}{l}\text { Whether the child attends playgroup/daycare/childcare/ } \\
\text { preschool/ kinder/school? }\end{array}$ \\
\hline & $\begin{array}{l}\text { Educational } \\
\text { development/ } \\
\text { resources }\end{array}$ & $\begin{array}{l}\text { Whether the teacher helps the child's educational development } \\
\text { (gives advice to parent about how they help child at home; gives } \\
\text { information community services that can help child; understands } \\
\text { needs of Indigenous families; informs parents about how to be } \\
\text { involved in school) }\end{array}$ \\
\hline $\begin{array}{l}\text { Emotional } \\
\text { wellbeing }\end{array}$ & Bullied & Whether the child has been bullied at school during the past year \\
\hline $\begin{array}{l}\text { Exposure to } \\
\text { risky behaviour }\end{array}$ & $\begin{array}{l}\text { Drug and } \\
\text { alcohol } \\
\text { problems }\end{array}$ & $\begin{array}{l}\text { Whether anyone in the household had an alcohol or drug } \\
\text { problem during the past year }\end{array}$ \\
\hline
\end{tabular}

Note: Indicators are based on the questionnaire items used in the Longitudinal Study of Indigenous Children (LSIC). 
Table 3 Child disadvantage headcount rates, disaggregated by indicator and age for all Australian children in LSAC

\begin{tabular}{|c|c|c|c|c|c|c|c|c|c|c|c|}
\hline \multirow{2}{*}{$\begin{array}{l}\text { Child's } \\
\text { age } \\
\text { (years) }\end{array}$} & \multicolumn{2}{|c|}{$\begin{array}{c}\text { Dimension 1: } \\
\text { Health }\end{array}$} & \multicolumn{2}{|c|}{$\begin{array}{c}\text { Dimension 2: } \\
\text { Family } \\
\text { relationships }\end{array}$} & \multirow{2}{*}{$\begin{array}{l}\text { Dimension 3: } \\
\text { Community } \\
\text { connectedness } \\
\text { Community } \\
\text { activities }\end{array}$} & \multicolumn{2}{|c|}{$\begin{array}{c}\text { Dimension 4: } \\
\text { Material } \\
\text { wellbeing }\end{array}$} & \multicolumn{2}{|c|}{$\begin{array}{c}\text { Dimension 5: } \\
\text { Educational } \\
\text { wellbeing }\end{array}$} & \multirow{2}{*}{$\begin{array}{c}\text { Dimension 6: } \\
\text { Emotional } \\
\text { wellbeing } \\
\text { Bullied }\end{array}$} & \multirow{2}{*}{$\begin{array}{c}\text { Dimension 7: } \\
\text { Risky } \\
\text { behaviour } \\
\text { Drug/alcohol }\end{array}$} \\
\hline & $\begin{array}{l}\text { Body } \\
\text { weight }\end{array}$ & $\begin{array}{l}\text { Medical } \\
\text { care }\end{array}$ & $\begin{array}{c}\text { Home } \\
\text { activities }\end{array}$ & $\begin{array}{l}\text { Outdoor } \\
\text { activities }\end{array}$ & & $\begin{array}{c}\text { Extra cost } \\
\text { activities }\end{array}$ & & $\begin{array}{c}\text { Talk about } \\
\text { school }\end{array}$ & $\begin{array}{l}\text { School } \\
\text { perform. }\end{array}$ & & \\
\hline $4-5$ & & $\begin{array}{c}0.0869 \\
(0.0880)\end{array}$ & $\begin{array}{c}0.0866 \\
(0.0885)\end{array}$ & $\begin{array}{c}0.0956 \\
(0.0955) \\
\end{array}$ & & & & & & & \\
\hline-7 & & $\begin{array}{c}0.0973 \\
(0.0993) \\
\end{array}$ & & & & & & & & & \\
\hline-9 & $\begin{array}{c}0.2423 \\
(0.2452) \\
\end{array}$ & $\begin{array}{c}0.1127 \\
(0.1117)\end{array}$ & $\begin{array}{c}0.0683 \\
(0.0704)\end{array}$ & $\begin{array}{c}0.1718 \\
(0.1760) \\
\end{array}$ & & $\begin{array}{c}0.0919 \\
(0.0983)\end{array}$ & $\begin{array}{c}0.0692 \\
(0.0707)\end{array}$ & $\begin{array}{c}0.0020 \\
(0.0020)\end{array}$ & $\begin{array}{c}0.0624 \\
(0.0641) \\
\end{array}$ & $\begin{array}{r}0.3 \\
(0.3 \\
\end{array}$ & \\
\hline $10-11$ & $\begin{array}{c}0.2733 \\
(0.2799) \\
\end{array}$ & $\begin{array}{c}0.0964 \\
(0.0974) \\
\end{array}$ & $\begin{array}{c}0.0655 \\
(0.0653) \\
\end{array}$ & $\begin{array}{c}0.2828 \\
(0.2835) \\
\end{array}$ & $\begin{array}{c}0.0433 \\
(0.0451) \\
\end{array}$ & $\begin{array}{c}0.0841 \\
(0.0873) \\
\end{array}$ & $\begin{array}{c}0.0267 \\
(0.0314) \\
\end{array}$ & $\begin{array}{c}0.0025 \\
(0.0025) \\
\end{array}$ & $\begin{array}{c}0.0723 \\
(0.0721) \\
\end{array}$ & $\begin{array}{c}0.2935 \\
(0.2936) \\
\end{array}$ & $\begin{array}{c}0.0281 \\
(0.0286) \\
\end{array}$ \\
\hline $12-13$ & $\begin{array}{c}0.2783 \\
(0.2802)\end{array}$ & $\begin{array}{c}0.0914 \\
(0.0918)\end{array}$ & $\begin{array}{c}0.0793 \\
(0.0801)\end{array}$ & $\begin{array}{c}0.3984 \\
(0.3985)\end{array}$ & $\begin{array}{c}0.0773 \\
(0.0785)\end{array}$ & $\begin{array}{c}0.2100 \\
(0.2140)\end{array}$ & $\begin{array}{c}0.0225 \\
(0.0246)\end{array}$ & $\begin{array}{c}0.0039 \\
(0.0040)\end{array}$ & $\begin{array}{c}0.0866 \\
(0.0875)\end{array}$ & $\begin{array}{c}0.2595 \\
(0.2637)\end{array}$ & $\begin{array}{c}0.0318 \\
(0.0328)\end{array}$ \\
\hline
\end{tabular}

Note: Headcount rates denote the proportion of children who are deemed disadvantaged for the particular indicator relative to the total sample. Numbers in parenthesis are headcount rates of disadvantage computed for the unbalanced panel sample. Sample size for the balanced panel: 3557 per age group. Sample size for the unbalanced panel: 4012 for 4-5 years; 3918 for 6-7 years; 3948 for 8-9 years; 3951 for 10-11 years; and 3747 for 12-13 years. Source: Longitudinal Study of Australian Children (LSAC) collected biennially from 2004 to 2012 , following children from the age of $4-5$ years to $12-13$ years. 
Table 4 Child disadvantage headcount rates, disaggregated by indicator and age for Indigenous children in LSIC

\begin{tabular}{|c|c|c|c|c|c|c|c|c|c|c|c|}
\hline \multirow{2}{*}{$\begin{array}{l}\text { Child's } \\
\text { age } \\
\text { (years) }\end{array}$} & \multirow{2}{*}{$\begin{array}{c}\text { Dimension 1: } \\
\text { Health } \\
\text { Body } \\
\text { weight }\end{array}$} & \multicolumn{2}{|c|}{$\begin{array}{c}\text { Dimension 2: } \\
\text { Family } \\
\text { relationships }\end{array}$} & \multicolumn{2}{|c|}{$\begin{array}{l}\text { Dimension 3: } \\
\text { Community } \\
\text { connectedness }\end{array}$} & \multicolumn{2}{|c|}{$\begin{array}{c}\text { Dimension 4: } \\
\text { Material } \\
\text { wellbeing }\end{array}$} & \multicolumn{2}{|c|}{$\begin{array}{c}\text { Dimension 5: } \\
\text { Educational } \\
\text { wellbeing }\end{array}$} & \multirow{2}{*}{$\begin{array}{c}\text { Dimension 6: } \\
\text { Emotional } \\
\text { wellbeing } \\
\text { Bullied }\end{array}$} & \multirow{2}{*}{$\begin{array}{c}\text { Dimension 7: } \\
\text { Risky } \\
\text { behaviour } \\
\text { Drug/alcohol }\end{array}$} \\
\hline & & $\begin{array}{c}\text { Home } \\
\text { activities }\end{array}$ & $\begin{array}{c}\text { Outdoor } \\
\text { activities }\end{array}$ & $\begin{array}{c}\text { Community } \\
\text { safety }\end{array}$ & $\begin{array}{l}\text { Community } \\
\text { suitability }\end{array}$ & $\begin{array}{c}\text { Housing } \\
\text { size }\end{array}$ & $\begin{array}{c}\text { Housing } \\
\text { quality }\end{array}$ & $\begin{array}{c}\text { School } \\
\text { attendance }\end{array}$ & $\begin{array}{l}\text { Educ. } \\
\text { resources }\end{array}$ & & \\
\hline $31 / 2-5$ & & $\begin{array}{c}0.0034 \\
(0.0064)\end{array}$ & & $\begin{array}{c}0.1276 \\
(0.1704)\end{array}$ & & & & & & & \\
\hline $41 / 2-6$ & $\begin{array}{c}0.2922 \\
(0.2837)\end{array}$ & $\begin{array}{c}0.0097 \\
(0.0121)\end{array}$ & $\begin{array}{c}0.0195 \\
(0.0225)\end{array}$ & $\begin{array}{c}0.1201 \\
(0.1419)\end{array}$ & $\begin{array}{c}0.1104 \\
(0.1280)\end{array}$ & $\begin{array}{c}0.5617 \\
(0.5692)\end{array}$ & $\begin{array}{c}0.3247 \\
(0.3408)\end{array}$ & & $\begin{array}{c}0.0877 \\
(0.0744)\end{array}$ & & \\
\hline $51 / 2-7$ & $\begin{array}{c}0.2918 \\
(0.2899)\end{array}$ & $\begin{array}{c}0.0066 \\
(0.0042)\end{array}$ & $\begin{array}{c}0.0197 \\
(0.0231)\end{array}$ & $\begin{array}{c}0.1246 \\
(0.1429)\end{array}$ & $\begin{array}{c}0.1148 \\
(0.1218)\end{array}$ & $\begin{array}{c}0.5770 \\
(0.5840)\end{array}$ & $\begin{array}{c}0.2656 \\
(0.3256)\end{array}$ & $\begin{array}{c}0.2164 \\
(0.2500)\end{array}$ & $\begin{array}{c}0.1836 \\
(0.1849)\end{array}$ & $\begin{array}{c}0.4230 \\
(0.4601)\end{array}$ & $\begin{array}{c}0.1672 \\
(0.1996)\end{array}$ \\
\hline $61 / 2-8$ & $\begin{array}{c}0.3259 \\
(0.3100)\end{array}$ & $\begin{array}{c}0.0288 \\
(0.0349)\end{array}$ & $\begin{array}{c}0.5048 \\
(0.5044)\end{array}$ & $\begin{array}{c}0.1022 \\
(0.1092)\end{array}$ & $\begin{array}{c}0.1054 \\
(0.1157)\end{array}$ & $\begin{array}{c}0.6230 \\
(0.6550)\end{array}$ & $\begin{array}{c}0.2620 \\
(0.3384)\end{array}$ & $\begin{array}{c}0.2173 \\
(0.2336)\end{array}$ & $\begin{array}{c}0.1693 \\
(0.1812)\end{array}$ & $\begin{array}{c}0.4473 \\
(0.4738)\end{array}$ & $\begin{array}{c}0.2428 \\
(0.2445)\end{array}$ \\
\hline $71 / 2-9$ & $\begin{array}{c}0.3439 \\
(0.3410)\end{array}$ & $\begin{array}{c}0.0510 \\
(0.0628)\end{array}$ & $\begin{array}{c}0.4204 \\
(0.4435)\end{array}$ & $\begin{array}{c}0.1019 \\
(0.1151)\end{array}$ & $\begin{array}{c}0.0955 \\
(0.1067)\end{array}$ & $\begin{array}{c}0.5860 \\
(0.5900)\end{array}$ & $\begin{array}{c}0.3185 \\
(0.3473)\end{array}$ & $\begin{array}{c}0.2389 \\
(0.2259)\end{array}$ & $\begin{array}{c}0.1720 \\
(0.2364)\end{array}$ & $\begin{array}{c}0.2962 \\
(0.3159)\end{array}$ & $\begin{array}{c}0.2197 \\
(0.2427)\end{array}$ \\
\hline $81 / 2-10$ & $\begin{array}{c}0.4581 \\
(0.4442)\end{array}$ & $\begin{array}{c}0.0613 \\
(0.1284)\end{array}$ & $\begin{array}{c}0.0194 \\
(0.0358)\end{array}$ & $\begin{array}{c}0.1161 \\
(0.1242)\end{array}$ & $\begin{array}{c}0.1032 \\
(0.1074)\end{array}$ & $\begin{array}{c}0.6226 \\
(0.6126)\end{array}$ & $\begin{array}{c}0.3484 \\
(0.3389)\end{array}$ & $\begin{array}{c}0.2581 \\
(0.2611)\end{array}$ & $\begin{array}{c}0.2097 \\
(0.2232)\end{array}$ & $\begin{array}{c}0.4581 \\
(0.4758)\end{array}$ & $\begin{array}{c}0.2226 \\
(0.2632)\end{array}$ \\
\hline
\end{tabular}

Note: Headcount rates denote the proportion of children who are deemed disadvantaged for the particular indicator relative to the total sample. Numbers in parenthesis are headcount rates of disadvantage for the unbalanced panel. Sample size for the balanced panel: 321 per age group. Sample size for the unbalanced panel: 706 for 31/2-5years; 655 for $4 \frac{1}{2}-6$ years; 591 for 51/2-7 years; 534 for 61/2-8 years; 529 for 71/2-9 years; and 488 for 81/2-10 years. Source: Longitudinal Study of Indigenous Children (LSIC) collected annually from 2008 to 2013 , following children from the age of $3 \frac{1}{2}-5$ years to $81 \frac{1}{2}-10$ years. 
Table 5 Child disadvantage headcount rates of disadvantage, comparison samples across common indicators and age groups

\begin{tabular}{lccc}
\hline $\begin{array}{l}\text { Indicator and } \\
\text { child's age (years) }\end{array}$ & $\begin{array}{c}\text { Indigenous children } \\
\text { in LSIC }\end{array}$ & $\begin{array}{c}\text { Indigenous children } \\
\text { in LSAC }\end{array}$ & $\begin{array}{c}\text { Non-Indigenous } \\
\text { children in LSAC }\end{array}$ \\
\hline Body weight & 0.235 & 0.326 & 0.211 \\
$4-5$ & 0.309 & 0.371 & 0.188 \\
6-7 & 0.438 & 0.371 & 0.239 \\
$8-9$ & & & \\
\hline Home activities & 0.009 & 0.079 & 0.087 \\
$4-5$ & 0.023 & 0.124 & 0.085 \\
6-7 & 0.071 & 0.079 & 0.068 \\
$8-9$ & & & \\
\hline Outdoor activities & 0.030 & 0.079 & 0.096 \\
$4-5$ & 0.362 & 0.213 & 0.143 \\
6-7 & 0.143 & 0.180 & 0.172 \\
$8-9$ & & & \\
\hline Bullied & 0.427 & 0.337 & 0.174 \\
$4-5$ & 0.402 & 0.438 & 0.301 \\
6-7 & 0.405 & 0.427 & 0.328 \\
$8-9$ & & & \\
\hline Drug/alcohol problems & 0.166 & 0.101 & 0.039 \\
$4-5$ & 0.220 & 0.045 & 0.019 \\
6-7 & 0.237 & 0.056 & 0.023 \\
\hline $8-9$ & &
\end{tabular}

Note: Headcount rates are reported only for the age groups and indicators that are common in both surveys. Indigenous children comprise the total sample of LSIC and are representative of the geographic dispersion of Indigenous population nationally across both urban and remote areas. Indigenous children in LSAC are representative of the relative size of the Indigenous population as a proportion of the total Australian population, but are not geographically representative of the Indigenous population across all remote areas. Sample size: 321 Indigenous children in LSIC; 89 Indigenous children in LSAC; and 3468 non-Indigenous children in LSAC. Source: Longitudinal Study of Australian Children (LSAC) (2004 to 2008) and Longitudinal Study of Indigenous Children (LSIC) (2009 to 2012). 
Figure 1 Disadvantage scores of all Australian children in LSAC

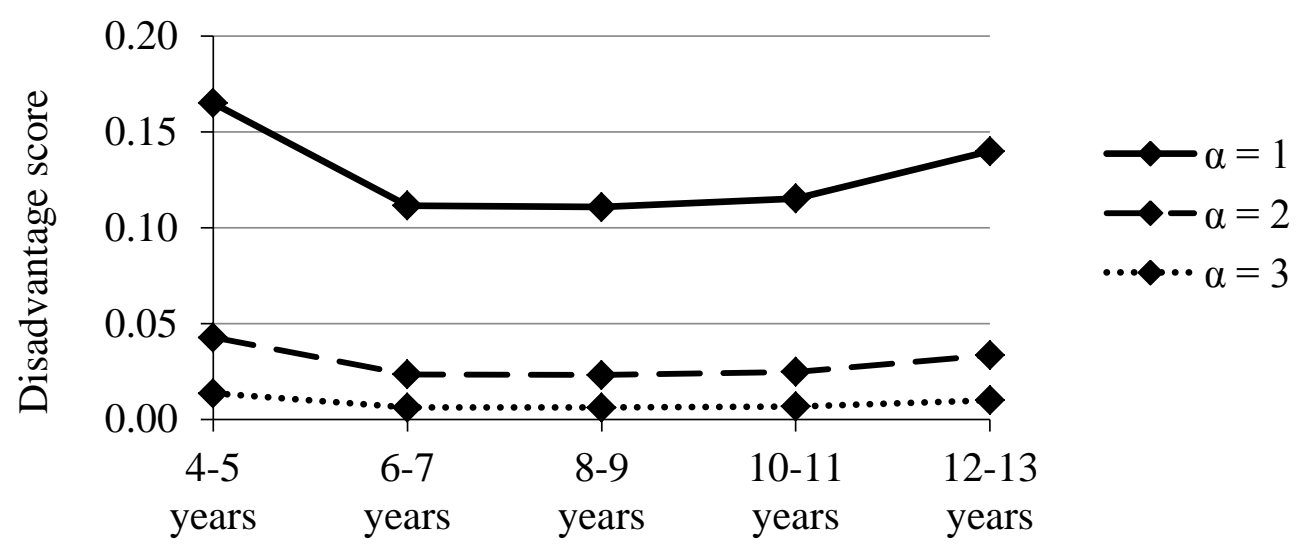

Note: Disadvantage scores are a multidimensional measure of aggregate disadvantage $\Omega_{\alpha}$ as defined in Equation (3) of the main text. The disadvantage scores presented in Figure 1 specifically represent $\Omega_{\alpha} \mid t$, calculated by setting $t=1$ in Equation (3) for each age group. Sample size: 3557 per age group. Source: Longitudinal Study of Australian Children (LSAC) collected biennially from 2004 to 2012, following children from the age of 4-5 years to 12-13 years.

Figure 2 Disadvantage scores of Indigenous children in LSIC

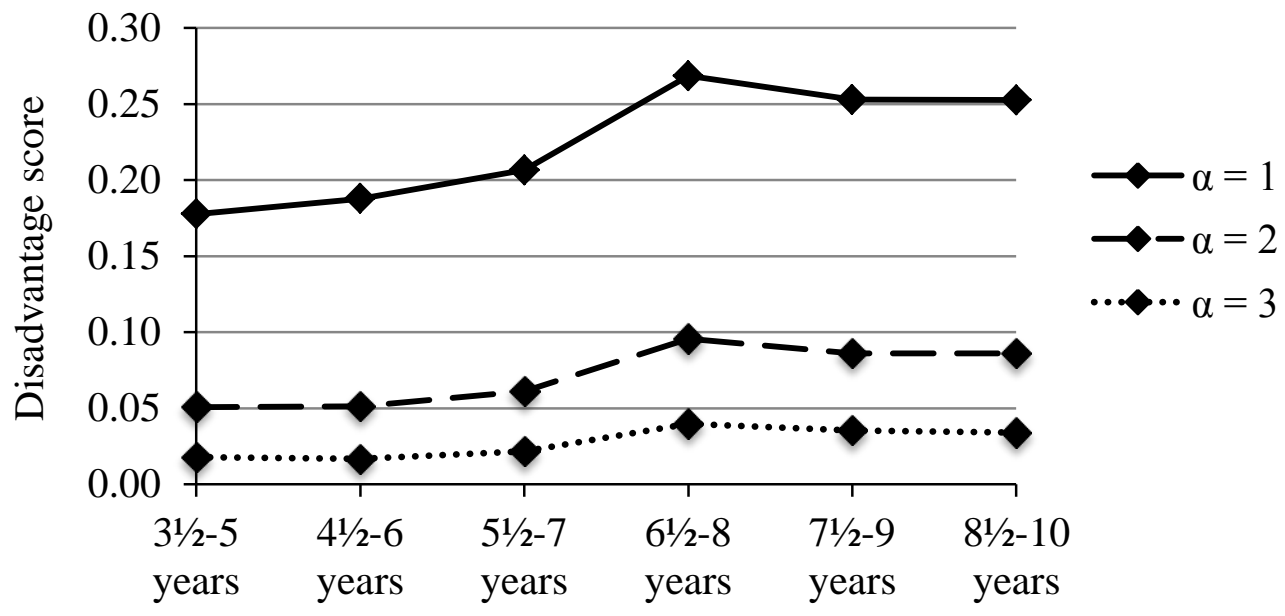

Note: Disadvantage scores are a multidimensional measure of aggregate disadvantage $\Omega_{\alpha}$ as defined in Equation (3) of the main text. The disadvantage scores presented in Figure 2 specifically represent $\Omega_{\alpha} \mid t$, calculated by setting $t=1$ in Equation (3) for each age group. Sample size: 321 per age group. Source: Longitudinal Study of Indigenous Children (LSIC) collected annually from 2008 to 2013, following children from the age of $3 \frac{1}{2}-5$ years to $8 \frac{1}{2}-10$ years. 
Figure 3 Disadvantage scores of all children and Indigenous/non-Indigenous subgroups in LSAC

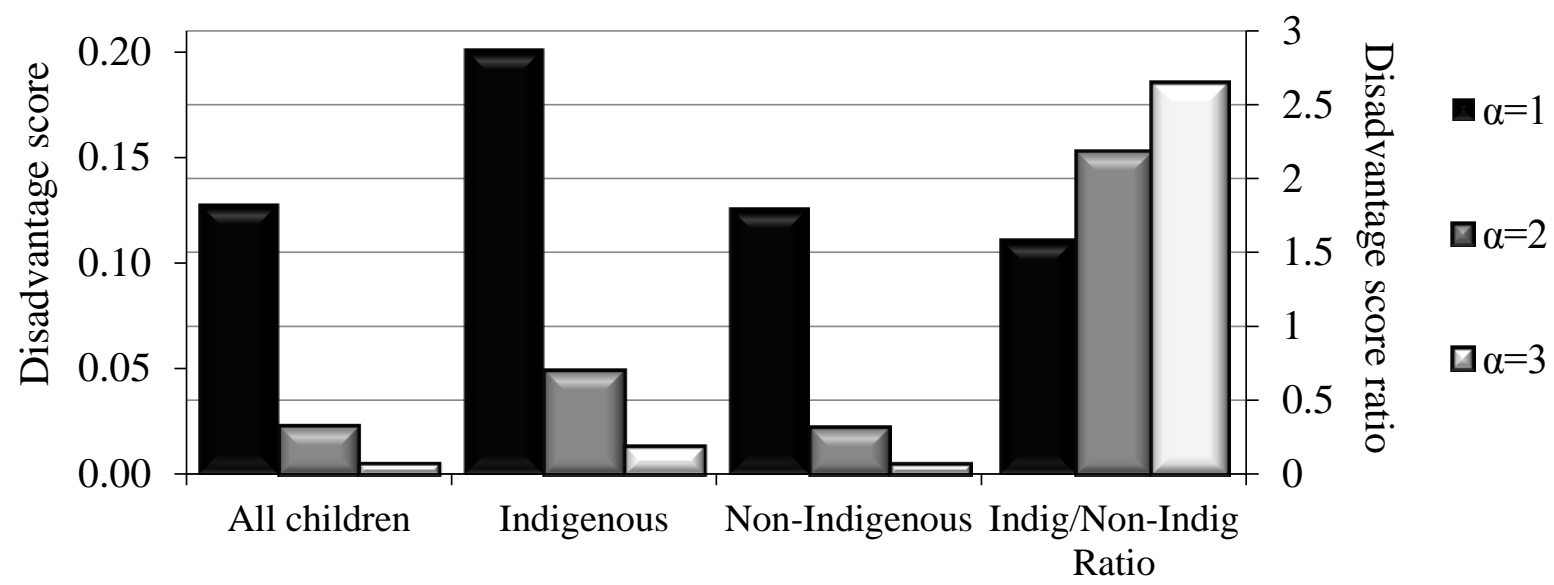

Note: Disadvantage scores are a multidimensional measure of aggregate disadvantage $\Omega_{\alpha}$ as defined in Equation (3) of the main text. The left-side $y$-axis corresponds to this disadvantage score, while the right-side $y$ axis corresponds to the ratio $\left(\left(\Omega_{\alpha}\right)_{\text {Indigenous }} /\left(\Omega_{\alpha}\right)_{\text {Non-Indigenous }}\right)$. Sample size: 89 Indigenous children and 3468 non-Indigenous children. Source: Longitudinal Study of Australian Children (LSAC) collected biennially from 2004 to 2012, following children from the age of 4-5 years to 12-13 years.

Figure 4 Disadvantage scores of all Indigenous children and high/low isolation subgroups in LSIC)

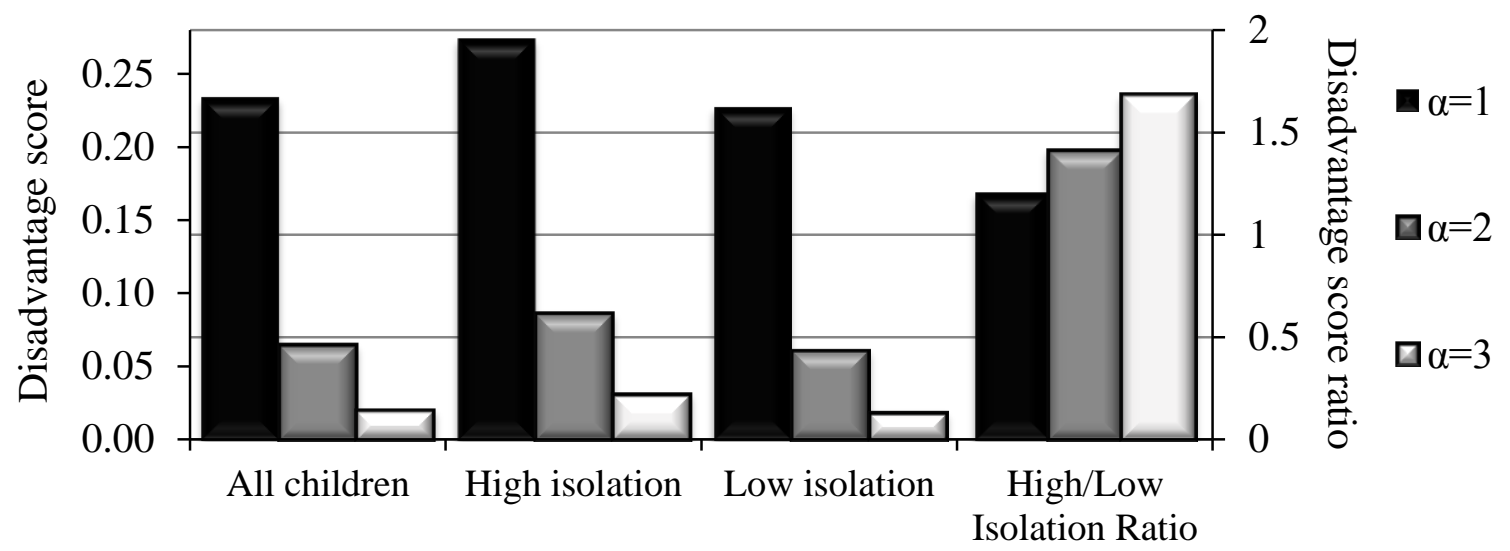

Note: Disadvantage scores are a multidimensional measure of aggregate disadvantage $\Omega_{\alpha}$ as defined in Equation (3) of the main text. The left-side $y$-axis corresponds to this disadvantage score, while the right-side $y$ axis corresponds to the ratio $\left(\left(\Omega_{\alpha}\right)_{\text {High isolation }} /\left(\Omega_{\alpha}\right)_{\text {Low isolation }}\right)$. Sample size: 276 children in high isolation and 45 children in low isolation. Source: Longitudinal Study of Indigenous Children (LSIC) collected annually from 2008 to 2013, following children from the age of $3 \frac{1}{2}-5$ years to $81 / 2-10$ years. 
Figure 5 Persistence-augmented disadvantage scores for all children and Indigenous/nonIndigenous children in LSAC

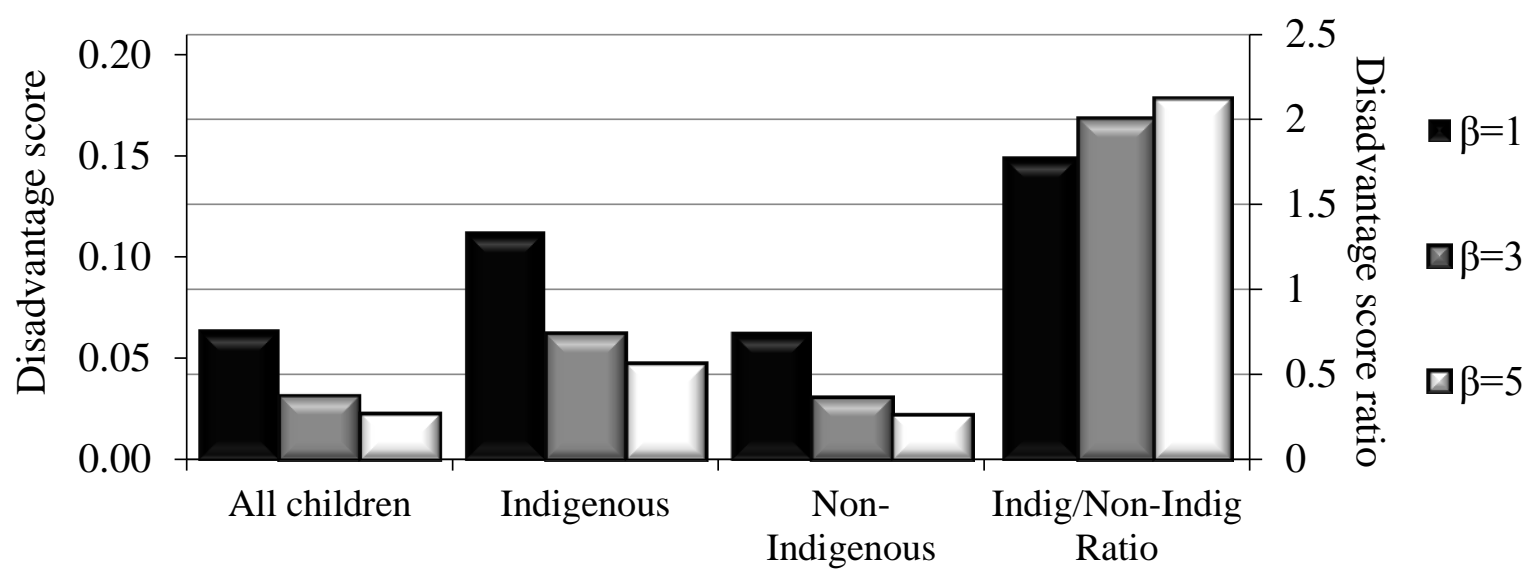

Note: Persistence-augmented disadvantage scores are a multidimensional measure of aggregate disadvantage $\mathrm{P} \Omega_{\alpha}$, adjusted for the effects of persistence as defined in Equation (4) in the main text. The scores are computed at values of $\alpha=1$ for illustrative purposes. The left-side $y$-axis corresponds to this disadvantage score, while the right-side $y$-axis corresponds to the ratio $\left(\left(\mathrm{P} \Omega_{\alpha}\right)_{\text {Indigenous }} /\left(\mathrm{P} \Omega_{\alpha}\right)_{\text {non-Indigenous }}\right)$. A ratio greater (less) than 1 shows that Indigenous children are more (less) disadvantaged than non-Indigenous children. Source: Longitudinal Study of Australian Children (LSAC) collected biennially from 2004 to 2012, following children from the age of 4-5 years to $12-13$ years.

Figure 6 Persistence-augmented disadvantage scores for all Indigenous children and high/low isolation subgroups in LSAC

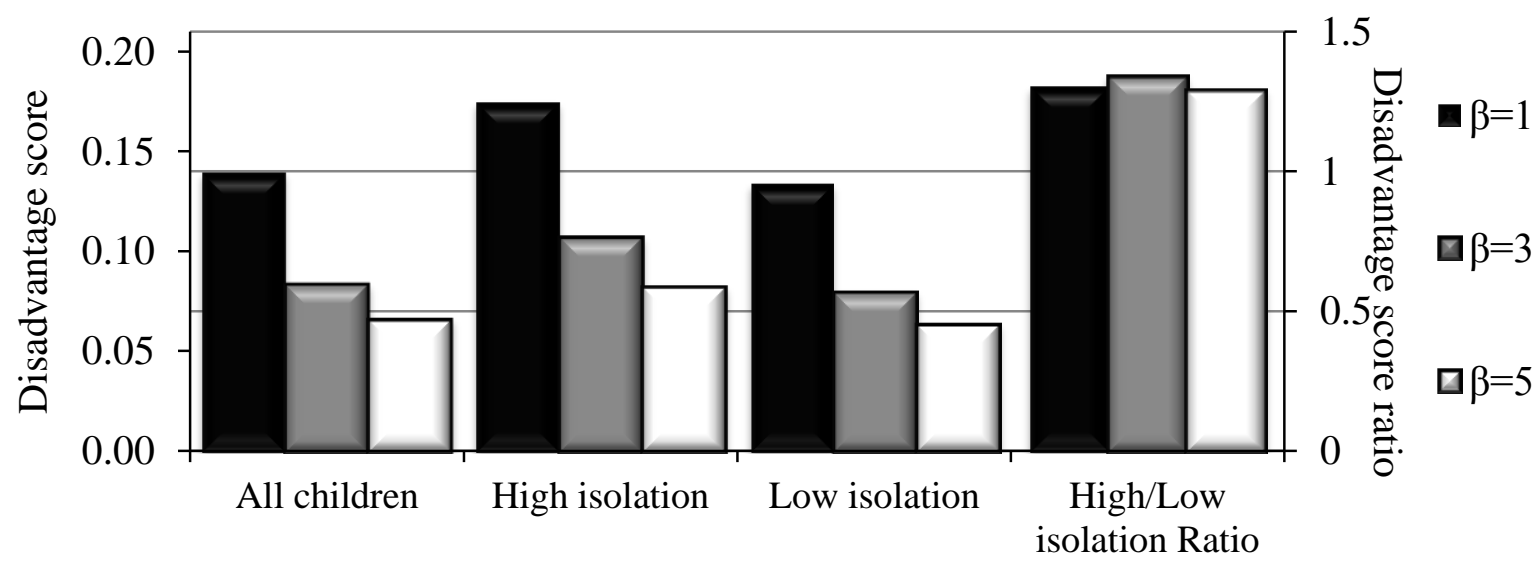

Note: Persistence-augmented disadvantage scores are a multidimensional measure of aggregate disadvantage $\mathrm{P} \Omega_{\alpha}$, adjusted for the effects of persistence as defined in Equation (4) in the main text. The scores are computed at values of $\alpha=1$ for illustrative purposes. The left-side $y$-axis corresponds to this disadvantage score, while the right-side $y$-axis corresponds to the ratio $\left(\left(\mathrm{P} \Omega_{\alpha}\right)_{\text {High isolation }} /\left(\mathrm{P} \Omega_{\alpha}\right)_{\text {Low isolation }}\right)$. A ratio greater (less) than 1 shows that Indigenous children in high isolated areas are more (less) disadvantaged than the children in low isolated areas. Sample size: 276 children in high isolation and 45 children in low isolation. Source: Longitudinal Study of Indigenous Children (LSIC) collected annually from 2008 to 2013, following children from the age of $3 \frac{1}{2}-5$ years to $8 \frac{1}{1 / 2}-10$ years. 
Figure 7 Ratio of indicator-specific persistence-augmented disadvantage scores for Indigenous/non-Indigenous children in LSAC

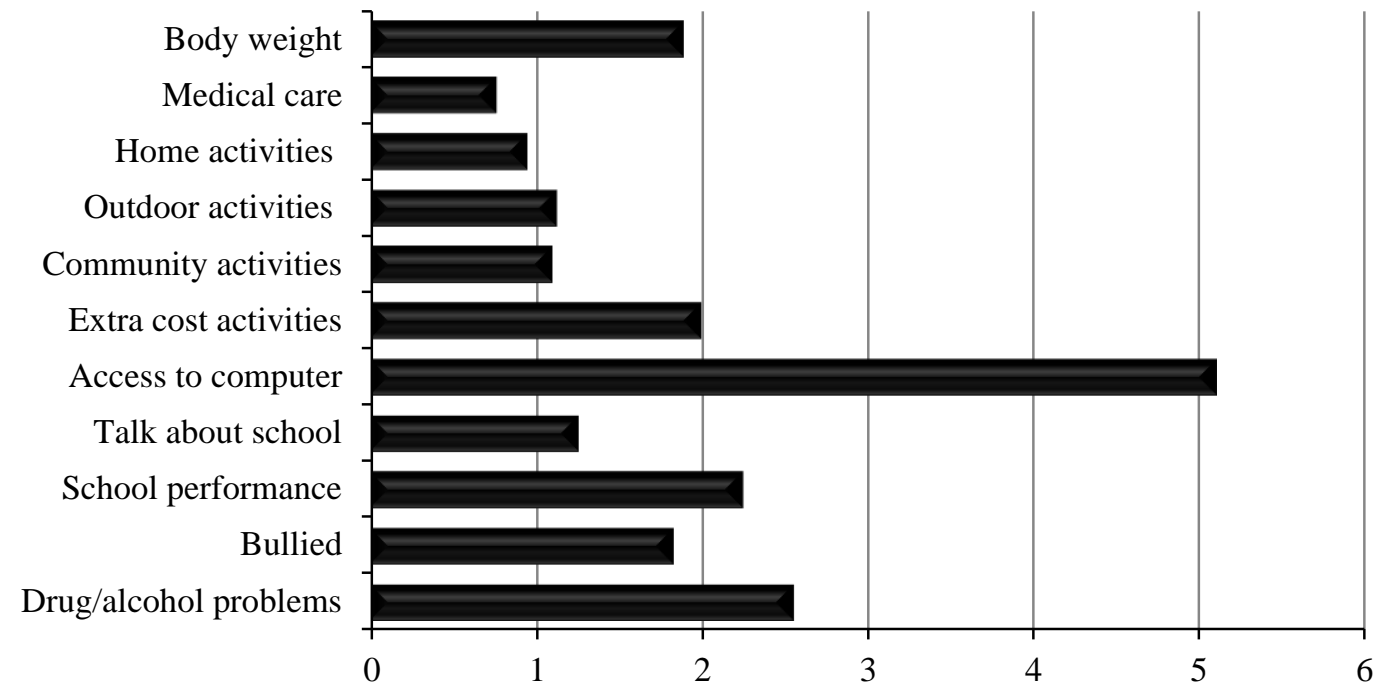

Note: Indicator-specific persistence-augmented disadvantage score is $\left.\mathrm{P} \Omega_{\alpha}\right|_{1}$ as defined in Equation (5) in the main text, with the ratio computed as $\left(\left(\left.\mathrm{P} \Omega_{\alpha}\right|_{1}\right)_{\text {Indigenous }} /\left(\left.\mathrm{P} \Omega_{\alpha}\right|_{1}\right)_{\text {Non-Indigenous }}\right)$. The scores are computed at values of $\alpha=1$ and $\beta=1$ for illustrative purposes. A ratio greater (less) than 1 shows that Indigenous children are more (less) disadvantaged than non-Indigenous children. Source: Longitudinal Study of Australian Children (LSAC) collected biennially from 2004 to 2012, following children from the age of 4-5 years to 12-13 years.

Figure 8 Ratio of indicator-specific persistence-augmented disadvantage scores for high/low isolation Indigenous children in LSIC

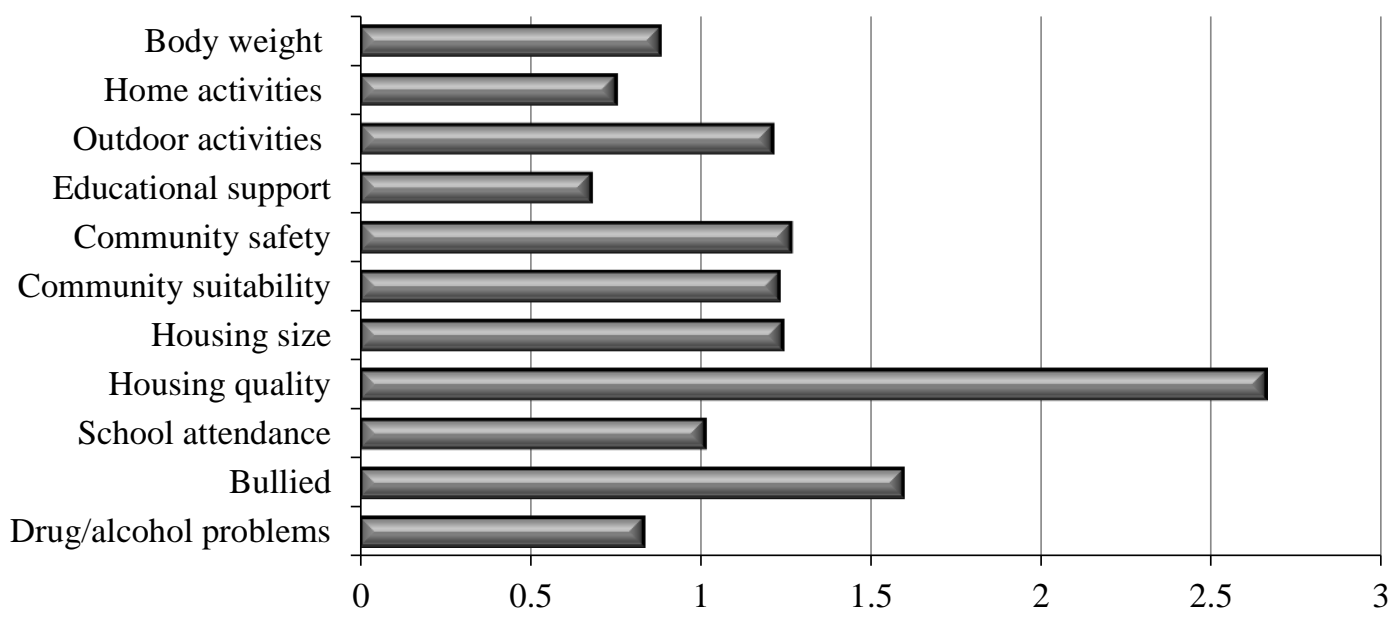

Note: Indicator-specific persistence-augmented disadvantage score is $\left.\mathrm{P} \Omega_{\alpha}\right|_{1}$ as defined in Equation (5) in the main text, with the ratio computed as $\left(\left.\mathrm{P} \Omega_{\alpha}\right|_{1}\right)_{\text {High isolation }} /\left(\left.\mathrm{P} \Omega_{\alpha}\right|_{1}\right)_{\text {Low isolation }}$. The scores are computed at values of $\alpha=1$ and $\beta=1$ for illustrative purposes A ratio greater (less) than 1 shows that Indigenous children in high isolated areas are more (less) disadvantaged than the children in low isolated areas. Sample size: 276 children in high isolation and 45 children in low isolation. Source: Longitudinal Study of Indigenous Children (LSIC) collected annually from 2008 to 2013 , following children from the age of $3 \frac{1}{2}-5$ years to $8 \frac{1}{12}-10$ years. 